\title{
B-learning para inducción del profesorado principiante. El caso del programa INDUCTIO en la República Dominicana
}

\section{B-learning for Induction of Novice Teachers. The Case of the INDUCTIO Program in the Dominican Republic}

\author{
Carlos Marcelo \\ Universidad de Sevilla \\ marcelo@us.es \\ Carmen Gallego-Domínguez \\ Universidad de Sevilla \\ cgallego@us.es \\ Cristina Mayor \\ Universidad de Sevilla \\ crismayr@us.es
}

\begin{abstract}
Resumen
En este artículo describimos el caso de un programa de inducción dirigido al profesorado principiante en el que se utilizan de manera intensiva los recursos digitales (b-learning) con diferentes objetivos: creación de comunidades de aprendizaje, reflexión, análisis de la práctica, comunicación, y como consecuencia de ello, contribución al desarrollo profesional. El programa que describimos lo denominamos INDUCTIO (Programa de formación para la inducción del profesorado principiante de la República Dominicana). El programa de formación INDUCTIO se fundamenta en una visión constructivista y conectivista de la formación docente. Además asume los principios de la autoformación y el desarrollo profesional docente basado en la evidencia. Coherente con esta visión, el programa plantea un amplio conjunto de experiencias de aprendizaje que facilita en los docentes principiantes una inserción de calidad en la docencia. En el programa están participando activamente 363 profesores principiantes y 45 mentores. El programa ofrece herramientas tecnológicas para el apoyo al proceso de inducción como son el diario reflexivo, los planes de mejora, los foros, la plataforma de contenidos online, el portal de recursos educativos, los círculos de aprendizaje, etc.
\end{abstract}

\section{Palabras clave}

Inducción, inserción, profesorado principiante, b-learning, mentor, comunidad de aprendizaje.

\footnotetext{
Abstract

In this article we describe the case of an induction programme for novice teachers in which digital resources (b-learning) with different objectives are used intensively: creating communities of learning, reflection and analysis of practice, communication, and as a result, contributing to professional development. The program that we describe is called INDUCTIO (programme for induction of novice teachers in the Dominican Republic). INDUCTIO is based on a constructivist and conectivist vision of teacher induction. Besides, we assume the principles of self-regulated learning and teacher professional development based on evidence. Consistent with this view, the program raises a wide range of learning experiences that can facilitate an inclusion of quality in beginning teachers. In the program, there are 363 beginning teachers and 45 mentors participating actively. The
} 
program provides technological tools for the support of the induction process: reflective journal, plans of improvement, forums, online platform of content, portal of educational resources, circles of learning, etc..

\section{Key words}

Induction, beginning teacher, b-learning, mentoring, learning community.

\section{Introducción}

Llegar a ser un buen docente es un trayecto largo e intenso. Las investigaciones nos muestran que en este trayecto hay una etapa que resulta crucial y que sistemáticamente ha sido desdeñada: los primeros años de inserción o inducción profesional a la docencia (Vaillant \& Marcelo, 2015). Cómo nos socializamos en los nuevos ambientes educativos determina la calidad del docente que podremos llegar a ser (Bickmore \& Bickmore, 2010; Kelly, Reushle, Chakrabarty, \& Kinnane, 2014; White, 2011).

La inducción profesional en la enseñanza, es el periodo de tiempo que abarca los primeros años, en los cuales los docentes han de realizar la transición desde estudiantes a enseñantes. Es un periodo de tensiones y aprendizajes intensivos en contextos generalmente desconocidos y durante el cual los docentes principiantes deben adquirir conocimiento profesional además de conseguir mantener un cierto equilibrio personal.

El periodo de inducción es una etapa diferenciada en el camino de convertirse en docente. No es un salto en el vacío entre la formación inicial y la formación continua sino que tiene un carácter distintivo y determinante para conseguir un desarrollo profesional coherente y evolutivo (Boerr Romero, 2011b; Cox, Beca, \& Cerri, 2014). Durante el periodo de inducción, los docentes principiantes tienen que cumplir dos tareas: deben enseñar y deben aprender a enseñar (Jensen, Sandoval-Hernández, Knoll, \& González, 2012). Independientemente de la calidad del programa de formación inicial que hayan cursado, hay competencias que sólo se aprenden en la práctica, y ello repercute en que este primer año sea un año de supervivencia, descubrimiento, adaptación, aprendizaje y transición.

Los primeros años en ocasiones representan un "choque con la realidad", es un proceso de intenso aprendizaje - del tipo ensayo-error en la mayoría de los casos-, y caracterizado por un principio de supervivencia, y por un predominio del valor de lo práctico. Los programas de inducción tratan de establecer estrategias para reducir o reconducir el denominado "choque con la realidad". Los docentes principiantes se encuentran con ciertos problemas específicos de su estatus profesional: el aislamiento de sus compañeros, la dificultad para transferir el conocimiento adquirido en su etapa de formación y el desarrollo de una concepción técnica de la enseñanza, son los problemas que más amenazan a los docentes principiantes. Otros problemas son: cómo gestionar el aula, cómo motivar a los alumnos, cómo relacionarse con los padres y con los compañeros, en definitiva, cómo sobrevivir personal y profesionalmente (Fetherston \& Lummis, 2012; Kelly et al., 2014).

Muy a menudo en algunos países, estas tensiones y desafíos derivan en el abandono temprano de la docencia. Así, en países como Estados Unidos la deserción se sitúa en

B-learning para inducción del profesorado principiante. El caso del programa INDUCTIO en la República Dominicana. Carlos Marcelo, Carmen Gallego-Domínguez y Cristina Mayor. 
torno al $30 \%$ en los cinco primeros años, mientras que en Australia se reduce al $20 \%$. El abandono se produce por estar insatisfechos con su trabajo debido a los bajos salarios, problemas de disciplina con los alumnos, falta de apoyo, y pocas oportunidades para participar en la toma de decisiones.

Para dar respuesta a las nuevas y complejas situaciones con las que se encuentran los docentes en la fase de inducción, se han configurado los programas que tienen como objetivo acompañar a los docentes principiantes a lo largo de sus primeros años de enseñanza (Bransford, Derry, Berliner \& Hammersness, 2005; Marcelo \& Vaillant, 2009). Se trata de programas formativos que pretenden ofrecer oportunidades no sólo apoyo emocional sino facilitar las competencias pedagógicas de los nuevos profesores (Barrera, Braley, \& Slate, 2010; Bickmore \& Bickmore, 2010; Kelly et al., 2014).

En el informe de Miradas sobre la Educación en Iberoamérica (Metas 2021), Desarrollo profesional docente y mejora de la educación, se destacaba la existencia de programas de mentoría en varios países Iberoamericanos, compartiendo todos ellos la idea de que la inducción a la docencia, como concepto, lleva consigo el acompañamiento de un profesor experimentado o mentor a alguien que se inicia en la profesión. Los programas más efectivos son aquellos que atraen con incentivos a los mejores mentores, a través de estándares de muy alta calidad y ofreciendo un entrenamiento previo para analizar y evaluar el proceso de enseñanza así como para poder conducir y crear discusiones sobre estos procesos complejos con los nuevos maestros (Robles Vásquez et al., 2013).

Si algo caracteriza a la mayoría de los programas de inducción es la figura del mentor. El mentor es un docente con experiencia y saber docente reconocido y con formación especializada como formador, que ofrece su apoyo al profesorado principiante (Kelly et al., 2014). En las dos últimas décadas los programas de inducción se han centrado en promover la relación entre un mentor y un principiante. Los resultados de investigación vienen a demostrar que este apoyo y acompañamiento hace que los docentes no abandonen su profesión (Bickmore \& Bickmore, 2010).

Pero la figura del mentor no es el único elemento que ayuda a hacer exitoso un programa de inducción. Otros componentes cada vez están tomando más importancia, como son las reuniones con colegas, seminarios de orientación, creación de redes, reducir carga lectiva, proporcionar un ayudante o asistente en el aula, escrituras reflexivas, observaciones y las prácticas de colaboración (Bang, 2013).

Pero mientras que los programas de inducción que se han venido organizando y desarrollando, han primado los contactos presenciales y síncronos, poco a poco se han venido introduciendo componentes $\mathrm{y}$ recursos que han permitido ampliar las posibilidades de comunicación, interacción y recursos ofrecidos al profesorado principiante (Romano, 2008). Elementos como los foros de discusión de docentes principiantes o la creación de redes específicas para docentes principiantes, permiten ofrecer a los docentes que inician un plus de acompañamiento ubicuo y distribuido (Zhao, Englert, Chen, Jones, \& Ferdig, 2000).

En este artículo describimos el caso de un programa de inducción dirigido al profesorado principiante en el que se utilizan de manera intensiva los recursos digitales (b-learning). El programa que describimos lo denominamos INDUCTIO (Programa de

B-learning para inducción del profesorado principiante. El caso del programa INDUCTIO en la República Dominicana. Carlos Marcelo, Carmen Gallego-Domínguez y Cristina Mayor. 
formación para inducción del profesorado principiante de la República Dominicana) surge a iniciativa del Instituto Nacional de Formación y Capacitación del Magisterio (INAFOCAM) de la República Dominicana, con el propósito de favorecer los procesos de inducción profesional a la docencia del profesorado principiante. Este proyecto se diseña y desarrolla por profesorado de la Universidad de Sevilla e INTEC (Instituto Tecnológico de Santo Domingo).

\section{Descripción del programa}

El programa INDUCTIO tiene como objetivo contribuir al desarrollo profesional docente del profesorado principiante a través de diferentes actividades: creación de comunidades de aprendizaje, reflexión, análisis de la práctica, comunicación, formación, etc.

INDUCTIO se fundamenta en una visión constructivista y conectivista de la formación docente. Además asume los principios de la autoformación y el desarrollo profesional docente basado en la evidencia. Coherente con esta visión, el programa plantea un amplio conjunto de experiencias de aprendizaje que pueden facilitar en los docentes principiantes una inserción de calidad en la docencia.

El programa consta de los siguientes componentes:

Seminarios formativos. A lo largo del primer año de docencia, el profesorado principiante participarán en seminarios formativos sobre temáticas basadas en las necesidades formativas surgidas en la literatura especializada en este campo, así como por el diagnóstico de necesidades formativas que se realiza para conocer las necesidades específicas de cada colectivo (en función del nivel escolar) o realidad (zonas rurales, vulnerables, multiculturales, etc.).

Mentor. Cada docente principiante tiene asignado un profesor mentor que le acompaña a lo largo de los dos primeros años de docencia. Cada mentor asesora a un número máximo de 10 profesores principiantes. La diada mentor-principiante incorpora procesos de planificación, enseñanza y evaluación. El profesor mentor realiza junto con el profesor principiante ciclos de planificación-observaciones de aula y análisis y reflexión sobre la enseñanza observada. Al menos se realiza un ciclo de planificaciónobservación-análisis cada mes.

Círculos de aprendizaje. Esta estrategia se presenta como un escenario informal de reflexión y análisis de problemáticas específicas de los docentes principiantes. Son espacios para compartir experiencias, intercambiar aprendizajes y reflexionar de forma colaborativa. Pueden ser un espacio para analizar videos de buenas prácticas de docentes enseñando, así como videos de los propios docentes principiantes para analizar su actividad diaria. También posibilita espacios para desarrollar la enseñanza entre iguales. Estos procesos son coordinados y dinamizados por al menos un profesor mentor. Se realiza al menos un círculo de aprendizaje de acompañamiento al mes, en el que participa el grupo de profesores principiantes al mentor asignado.

Portal de recursos digitales para docentes principiantes. Paralelamente al desarrollo del programa, se ha construido un Portal en internet que ofrece al profesorado principiante una amplia variedad de recursos y herramientas para el aprendizaje de los profesores. Consta al menos de los siguientes componentes: red social para docentes

B-learning para inducción del profesorado principiante. El caso del programa INDUCTIO en la República Dominicana. Carlos Marcelo, Carmen Gallego-Domínguez y Cristina Mayor. 
principiantes; foros de discusión; acceso a docentes expertos; materiales didácticos; ejemplos de buenas prácticas docentes; portafolio de aprendizaje; contenidos digitales, etc.

Representamos el programa que proponemos a través de la siguiente figura que plantea un conjunto de experiencias de aprendizaje dirigidas a facilitar la inserción de calidad del profesorado principiante. Como hemos señalado, este programa consta de Actividades formativas a desarrollar en el interior de la escuela y fuera de ella. Las actividades en el interior de la escuela toman en consideración la necesidad de que las escuelas, todas las escuelas, elaboran un plan de acogida para los nuevos profesores. Además, y éste es un elemento fundamental del programa, se establece la necesidad de desarrollar ciclos de análisis y mejora de la práctica que los profesores principiantes desarrollan junto con sus profesores mentores.

\section{Portal de recursos digitales para la docencia}

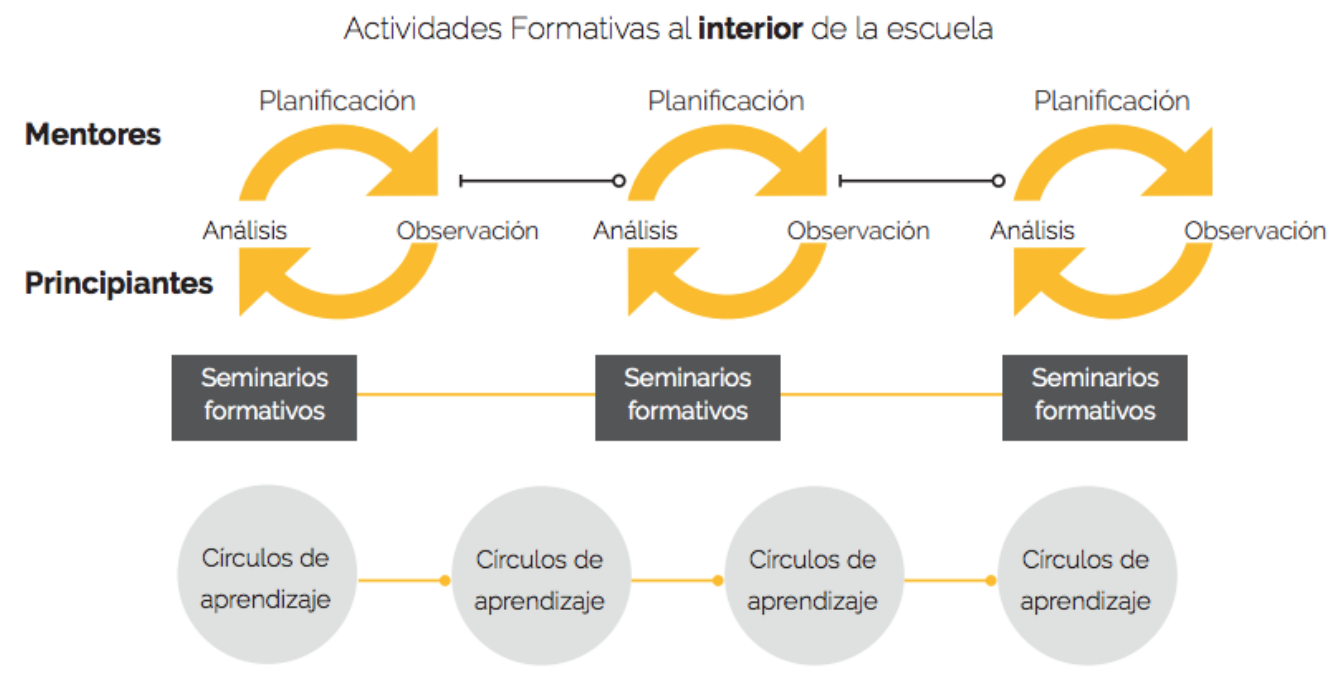

Actividades Formativas fuera de la escuela

Para desarrollar en el exterior de la escuela, se propone la realización de un conjunto de actividades formativas formales, como son la realización de seminarios formativos dirigidos a promover un mayor conocimiento acerca de los aspectos didácticos y organizativos de la función docente, que representan problemas para la inserción del profesorado principiante. Junto a estos seminarios, se propone la organización de actividades no formales, que denominamos Círculos de aprendizaje, a través de los cuales los profesores principiantes compartes, reflexionan e intercambian experiencias con otros docentes principiantes y experimentados. Por otra parte, a lo largo de todo el programa, los participantes disponen del Portal de Recursos Digitales para la Docencia, que les ofrece recursos y herramientas para aprender en los espacios virtuales.

Para que un programa de estas características tenga éxito se requiere un continuo monitoreo y evaluación. Por ello se diseña un modelo de evaluación del programa que 
va recabando y analizando la información a partir de diferentes fuentes de información (cuestionarios, entrevistas, observaciones) y de diferentes informantes (profesores principiantes, mentores, directores de escuela, formadores) para poder tomar decisiones para la mejora del programa en años sucesivos.

El programa se inicia en septiembre de 2015, y actualmente están participando activamente en INDUCTIO 363 profesores principiantes y 45 mentores. Del total de los principiantes participantes en el programa, el $85 \%$ son mujeres y el $15 \%$ hombres. En cuanto a la edad de los docentes principiantes participantes activos en el programa, un $34 \%$ de ellos tienen edades comprendidas entre 21 y 30 años; un $28 \%$ de los docentes tienen entre 31 y 45 años; y por último, el 38\% restante de ellos tienen edades comprendidas entre 46 y 53 años. Estos datos demuestran que la mayor parte de los docentes seleccionados para ser acompañados por los mentores tienen una edad comprendida entre 21 y 45 años, siendo un dato también relevante el hecho de que haya muchos de ellos que se acaban de iniciar en la docencia y tienen edades avanzadas (hablamos de más de 46 años).

\section{Metodología: plataforma de recursos digitales (b-learning) para el apoyo al proceso de inducción del profesorado principiante}

Describimos a continuación cada una de las herramientas que componen la plataforma formativa de INDUCTIO, aportando evidencias tanto textuales como fotográficas, así como tablas descriptivas de la estructura de uso de cada una de estas herramientas.

El programa INDUCTIO hace un uso intensivo de las tecnologías digitales como soporte para la comunicación, interacción, apoyo y aprendizaje. INDUCTIO ha desarrollado un portal en internet (http://inductio.org) que cuenta con un espacio abierto y público y un espacio privado para el acceso del profesorado principiante y mentores. El espacio abierto cuenta con un Fondo de conocimiento que ofrece al profesorado principiante una amplia variedad de recursos y herramientas para el aprendizaje. Consta de los siguientes componentes: red social para docentes principiantes; foros de discusión; acceso a docentes expertos; materiales didácticos; ejemplos de buenas prácticas docentes; portafolio de aprendizaje; contenidos digitales, etc.

B-learning para inducción del profesorado principiante. El caso del programa INDUCTIO en la República Dominicana. Carlos Marcelo, Carmen Gallego-Domínguez y Cristina Mayor. 


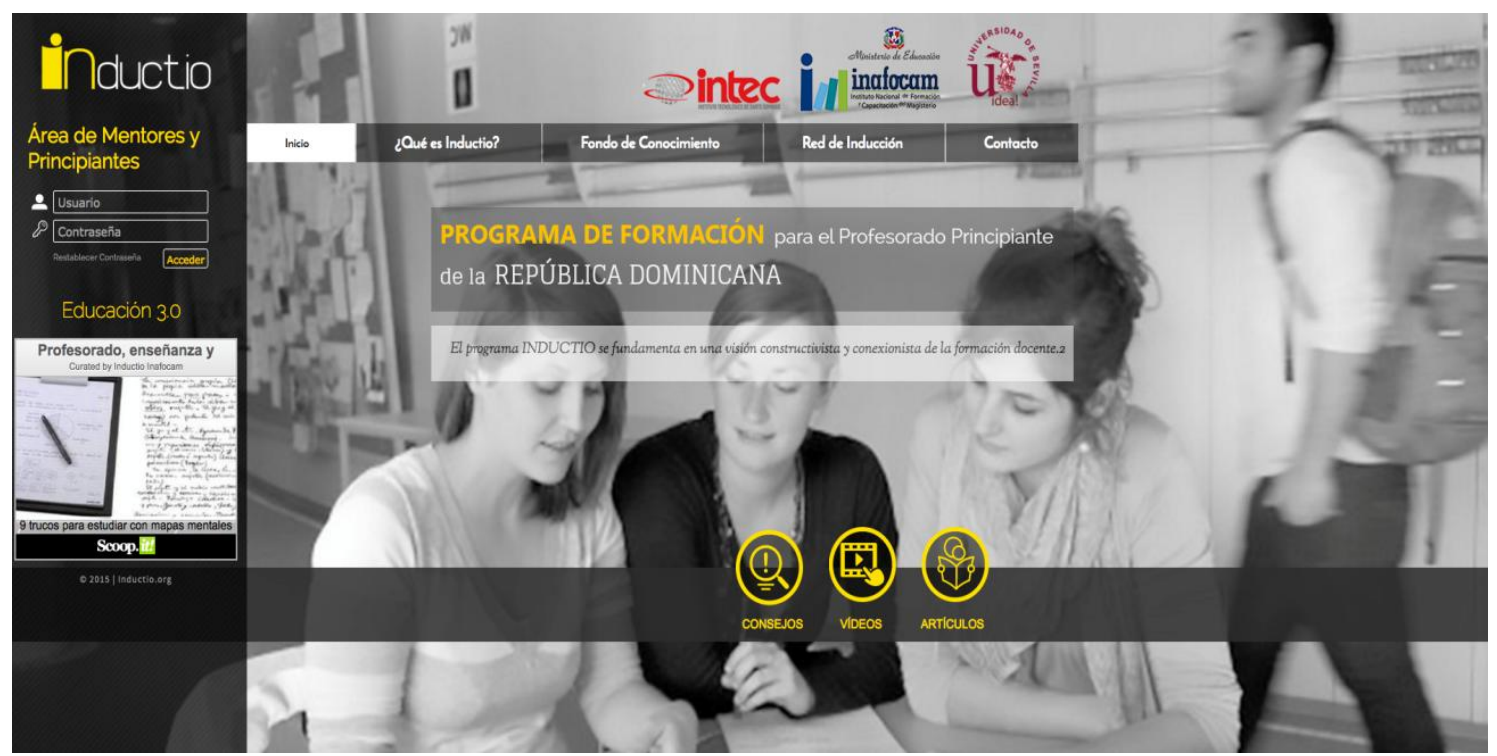

Imagen del portal en internet de INDUCTIO (www.inductio.org).
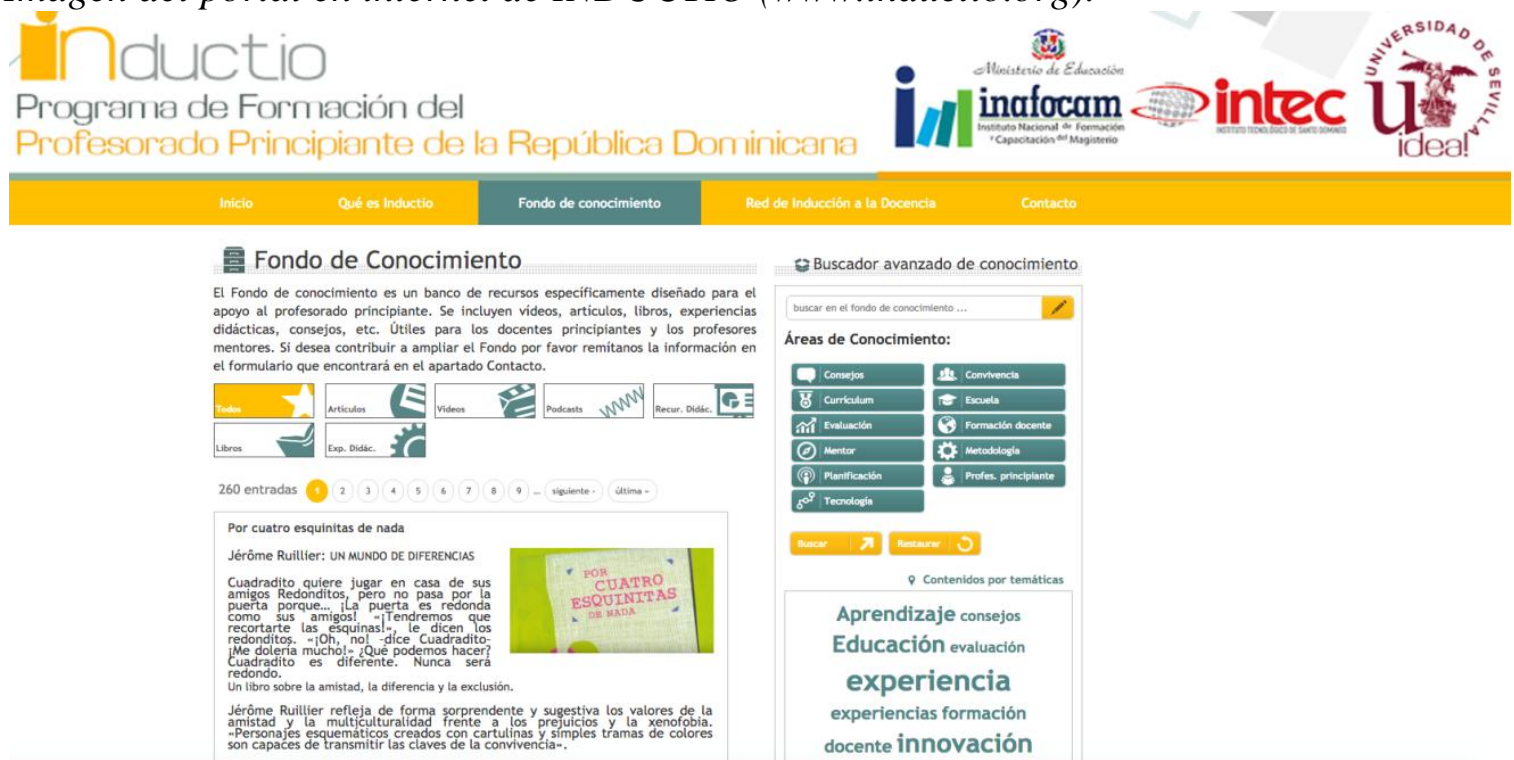

Imagen del Fondo de Conocimiento de INDUCTIO.

B-learning para inducción del profesorado principiante. El caso del programa INDUCTIO en la República Dominicana. Carlos Marcelo, Carmen Gallego-Domínguez y Cristina Mayor. 


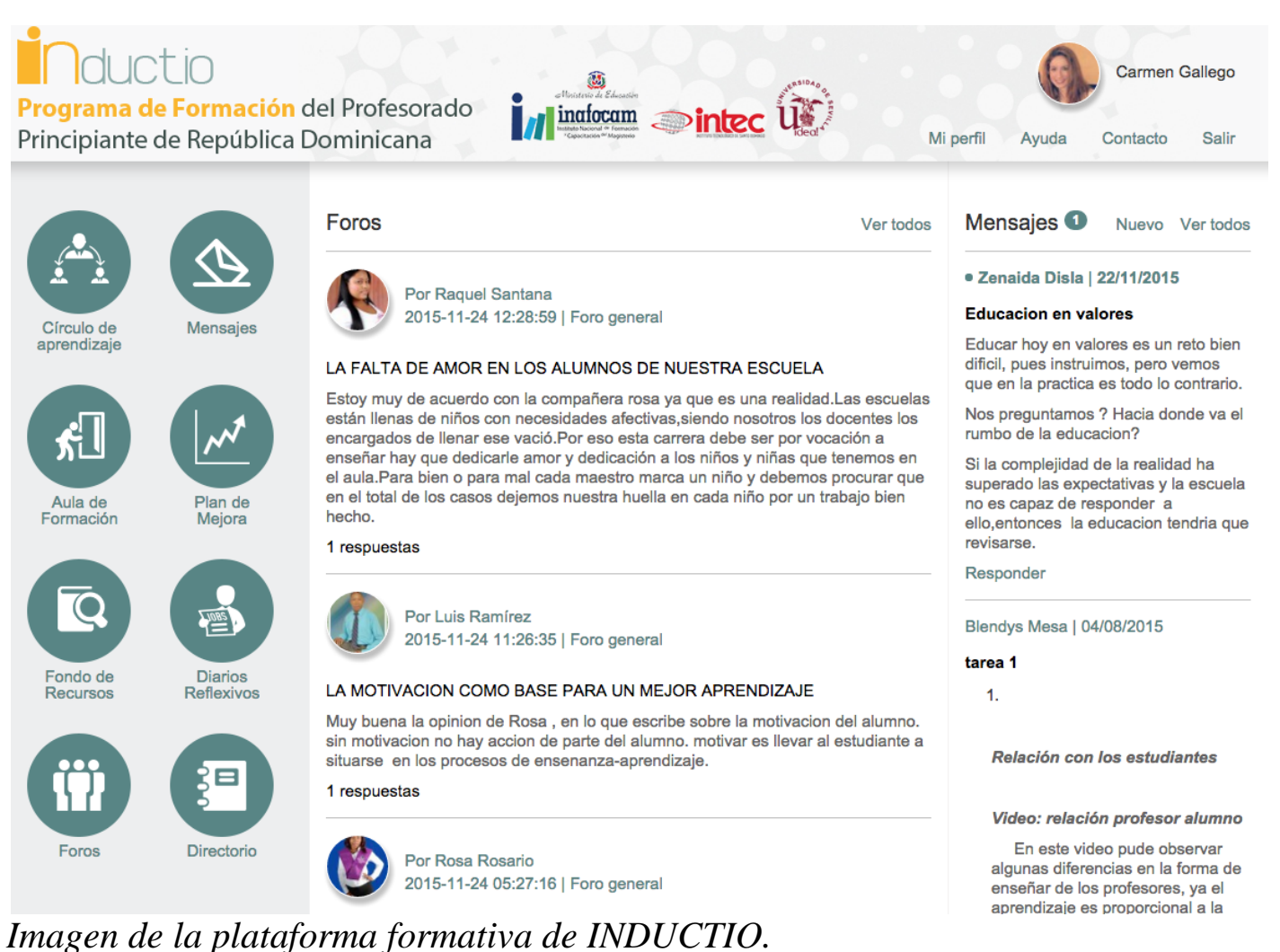

En el espacio privado de INDUCTIO se ofrece al profesorado principiante y a los mentores las siguientes herramientas, las cuales describimos y evidenciamos el efecto con textos, imágenes y tablas de frecuencias:

Los círculos de aprendizaje son los encuentros en los que cada mentor se reúne con todos los profesores principiantes que tiene asignados. Los círculos de aprendizaje son una ocasión para reflexionar conjuntamente sobre la enseñanza y sus posibilidades de mejora. Los círculos deben de estar preparados con antelación por parte del profesor mentor y los principiantes, acordando fechas y temáticas. En este espacio los mentores y principiantes redactan un informe de cada círculo desarrollado.

Los mentores están trabajando con esta herramienta al menos una vez al mes, citándose con sus principiantes y socializando temáticas problemáticas, intereses, buscando alternativas a imprevistos, dificultades, etc.

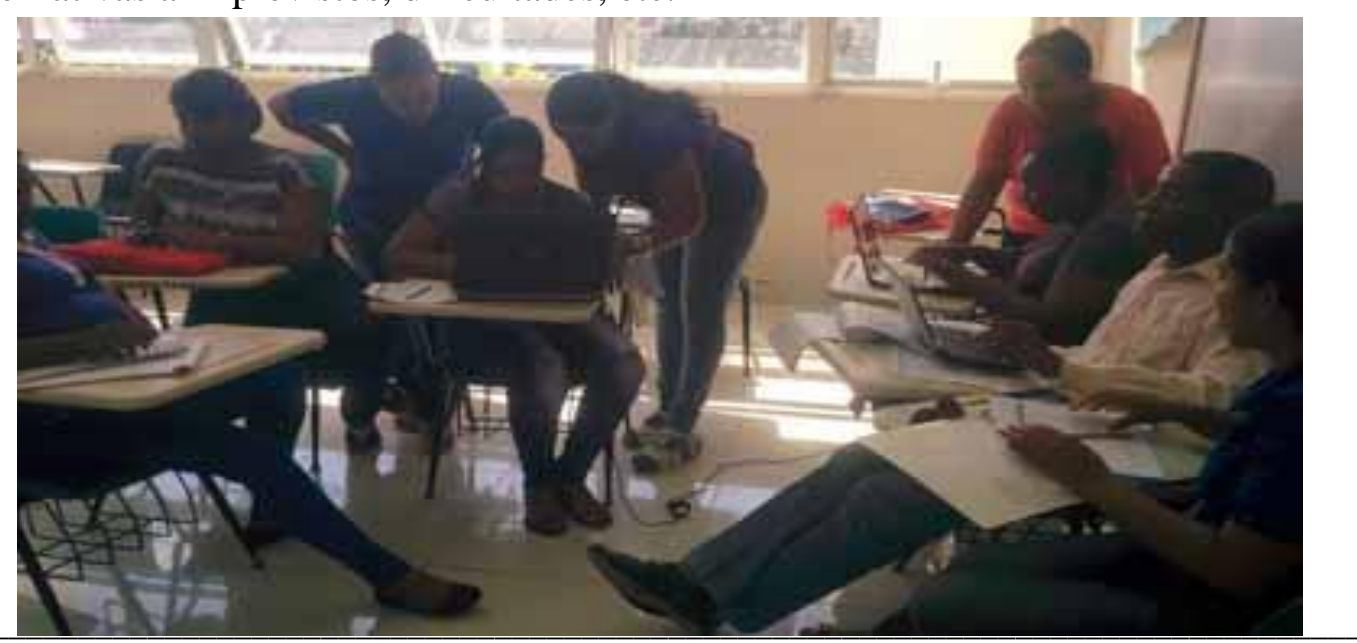

B-learning para inducción del profesorado principiante. El caso del programa INDUCTIO en la República Dominicana. Carlos Marcelo, Carmen Gallego-Domínguez y Cristina Mayor.

Página 8 de 28 
Tal y como observamos en estas imágenes, los docentes principiantes trabajan con sus computadoras sobre la plataforma y portal de INDUCTIO, siempre bajo el apoyo y orientación de su mentor. Tanto principiantes como mentores señalan la importancia de esta herramienta para estandarizar apoyos y reuniones, señalando dificultades y anotando descripciones sobre cómo actuar según el tema trabajado, por ejemplo:

"Nosotros cuando nos reunimos a socializar lo hacemos con las computadoras. Así vamos anotando en el Portal los temas trabajados y los intereses sobre los que hablamos. Así queda constancia de todo ello." (Mentora_33).
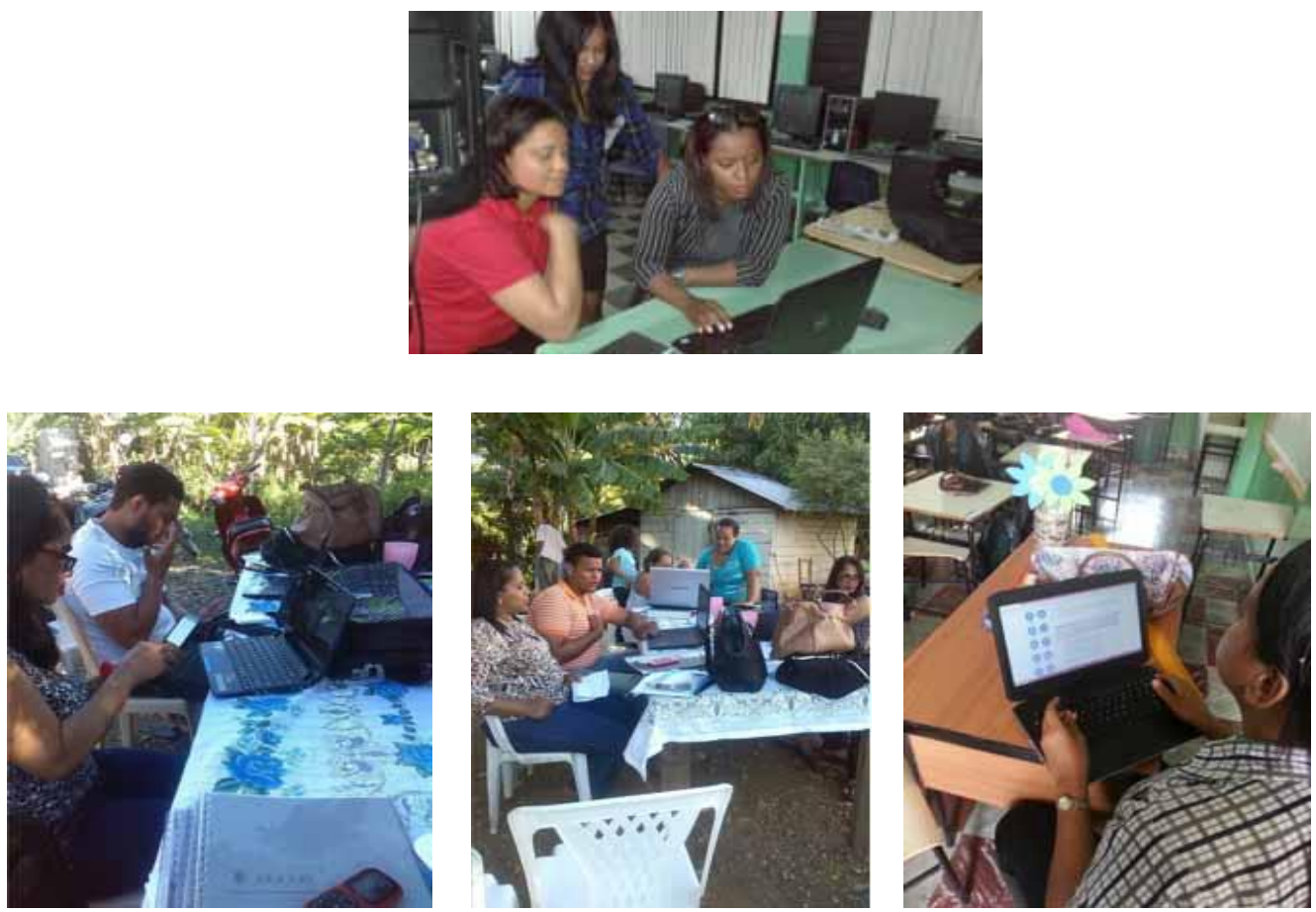

En estas imágenes comprobamos el apoyo y asesoramiento personalizado que los mentores y mentoras ofrecen a los docentes noveles en sus centros educativos. Los círculos de aprendizaje suelen desarrollarse en los centros educativos, pero también ha habido ocasiones en las que las reuniones se han celebrado en el hogar de los mentores.

"Nos reunimos en mi casa porque en los centros no había posibilidad de hacer uso de internet. En mi vivienda pudimos trabajar con el portal de INDUCTIO y con esta herramienta de manera cómoda”. (Mentora_7).

La estructura de los círculos de aprendizaje así como su efecto en el aprendizaje y mejora de la práctica en los docentes principiantes lo mostramos en la siguiente tabla:

\begin{tabular}{|c|c|}
\hline $\begin{array}{l}\text { Estructura de los círculos de } \\
\text { aprendizaje }\end{array}$ & \\
\hline $\begin{array}{l}\text { emáticas a abordar } \\
\text { cta de socialización y debate } \\
\text { onclusiones } \\
\text { ropuestas de mejora, acciones }\end{array}$ & $\begin{array}{l}\text { enseñanza y sus posibilidades de me } \\
\text { También ayuda a los mentores a estanda } \\
\text { su apoyo, crear líneas de debate en base } \\
\text { necesidades manifestadas por doce } \\
\text { compartir inquietudes, problemas, recu } \\
\text { motivaciones, etc. Del mismo modo }\end{array}$ \\
\hline
\end{tabular}

B-learning para inducción del profesorado principiante. El caso del programa INDUCTIO en la República Dominicana. Carlos Marcelo, Carmen Gallego-Domínguez y Cristina Mayor. 
emprender

Planeación del siguiente encuentro también les permite planear próximos encuentros, fijas metas y comprobar anteriores, detallar líneas de acción, recursos, etc.

$\triangle$ Se ofrece esta herramienta para poder enviar mensajes a los participantes en el programa. A través de los mensajes grupales, tanto principiantes como docentes comparten comentarios con el resto de participantes en el programa. Es una herramienta muy útil para debatir, mostrar sus posturas ante una temática, consultar dudas, etc. En definitiva, se trata de una herramienta que ofrece el Portal para construir de manera conjunta el conocimiento y aprender de manera colaborativa. Pueden enviar mensajes a todo el grupo, a un mentor en concreto, a un facilitador, profesor principiante, docente de la Universidad, etc.

En las siguientes imágenes podemos observar algunos ejemplos de temáticas introducidas por algún participante así como los mensajes y comentarios que los demás van añadiendo.

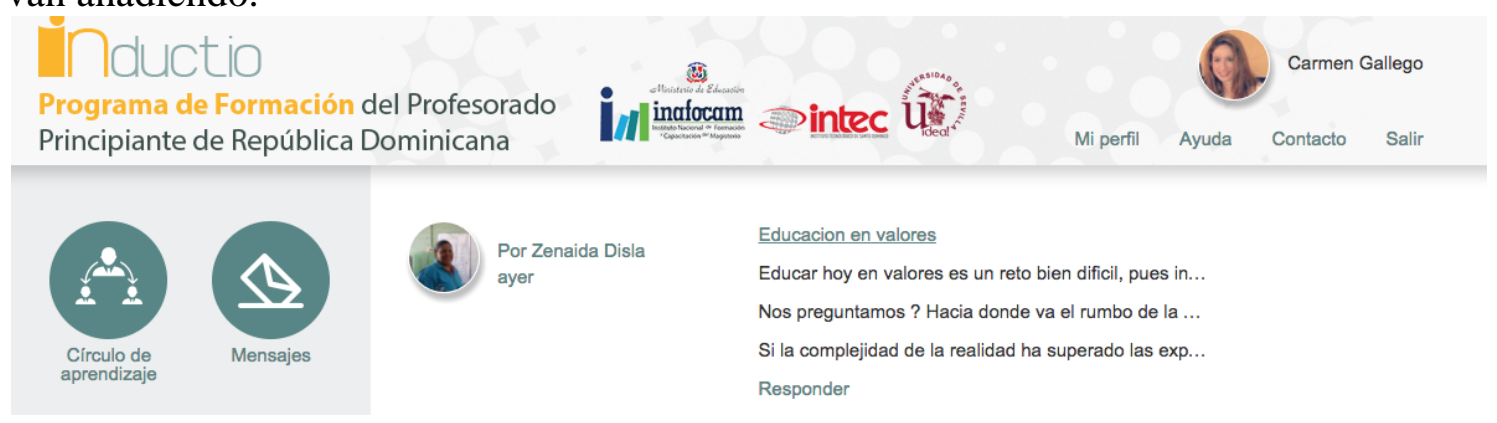

Cliqueando sobre el "asunto" del mensaje se accede al mensaje completo que el participante ha enviado.

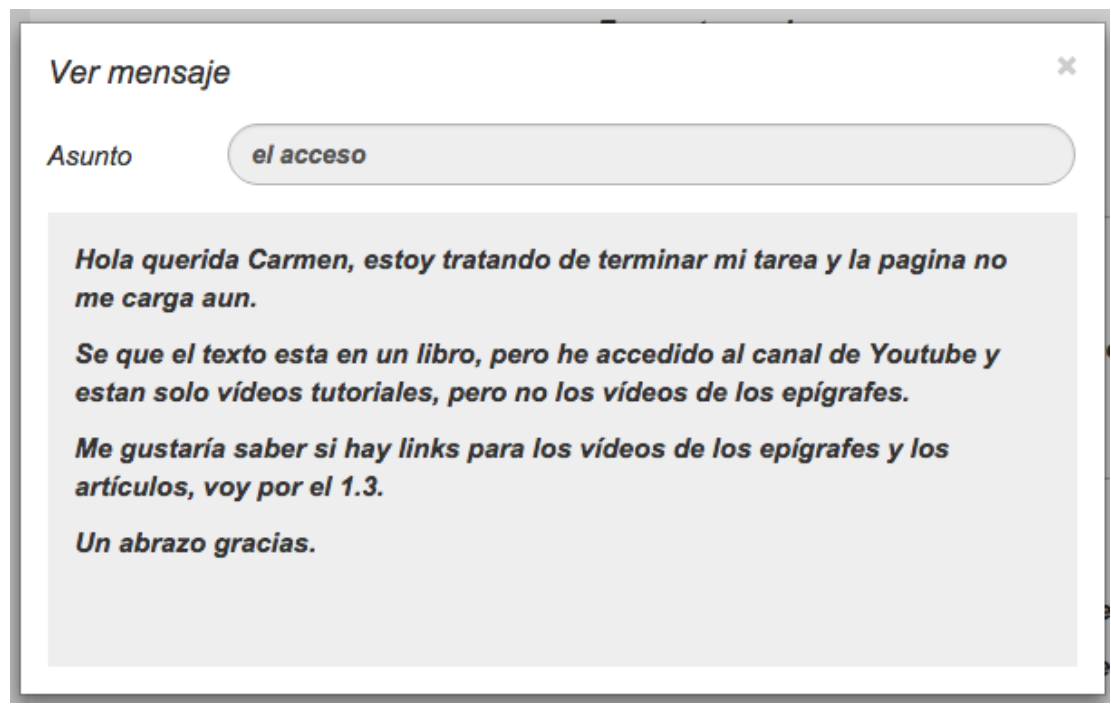

B-learning para inducción del profesorado principiante. El caso del programa INDUCTIO en la República Dominicana. Carlos Marcelo, Carmen Gallego-Domínguez y Cristina Mayor. 
En la siguiente tabla mostramos las temáticas de los mensajes enviados a través de esta herramienta, así como los usos que está teniendo:

\begin{tabular}{|l|l|}
\hline Temáticas de los mensajes & $\begin{array}{l}\text { Efectos de la herramienta en el aprendizaje y en la } \\
\text { formación de mentores y principiantes }\end{array}$ \\
\hline $\begin{array}{l}\text { Dudas técnicas del uso de } \\
\text { herramientas }\end{array}$ & $\begin{array}{l}\text { Permite compartir dudas, buscar soluciones entre todos, } \\
\text { socializar las resoluciones, desenvolverse por la } \\
\text { plataforma con ayuda de las indicaciones de los } \\
\text { compañeros, etc. }\end{array}$ \\
\hline $\begin{array}{l}\text { Dudas con la elaboración } \\
\text { de las tareas }\end{array}$ & $\begin{array}{l}\text { Produce un aprendizaje de manera cooperativa, ya que a } \\
\text { través de los mensajes los principiantes y mentores } \\
\text { envían sus cuestiones o dudas a la plataforma y entre } \\
\text { todos tratamos de dar respuesta a sus consultas. }\end{array}$ \\
\hline $\begin{array}{l}\text { Socialización de conflictos } \\
\text { en la escuela }\end{array}$ & $\begin{array}{l}\text { Los principiantes envían mensajes a la plataforma para } \\
\text { contar lo que les ha sucedido en el aula, suelen ser } \\
\text { temáticas de conflictos entre estudiantes, por lo que } \\
\text { mentores y docentes de otras escuelas dan su opinión } \\
\text { acerca de cómo mejorar la disciplina y cómo ellos } \\
\text { resuelven este tipo de conflictos en sus aulas cuando } \\
\text { sucede. }\end{array}$ \\
\hline $\begin{array}{l}\text { Compartir experiencias de } \\
\text { aula }\end{array}$ & $\begin{array}{l}\text { Aprenden a compartir, cooperar, construir aprendizaje } \\
\text { conjuntamente, etc. También difunden buenas prácticas } \\
\text { educativas fundamentadas en el ensayo en el aula y que } \\
\text { pueden funcionar en el salón de clase de otros docentes. }\end{array}$ \\
\hline
\end{tabular}

El Aula de Formación da acceso al Aula virtual que se desarrolla en la plataforma Moodle y que ofrece contenidos formativos online para el profesorado principiante así como para los mentores.

Los principiantes y mentores, al acceder con su clave y usuario visualizan la pantalla anterior incluida como imagen. En ella cliquean según sean principiantes o mentores.

En el aula de formación para mentores encuentran esta plataforma: 


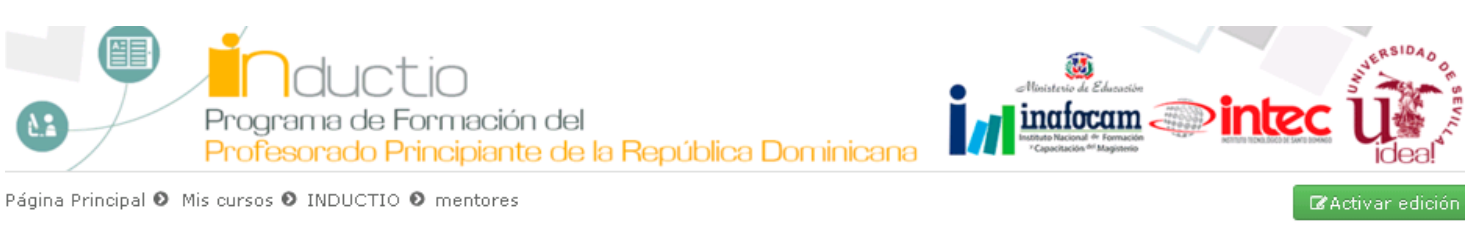

Diplomado en Formación del Profesorado Principiante. Especialidad Mentores

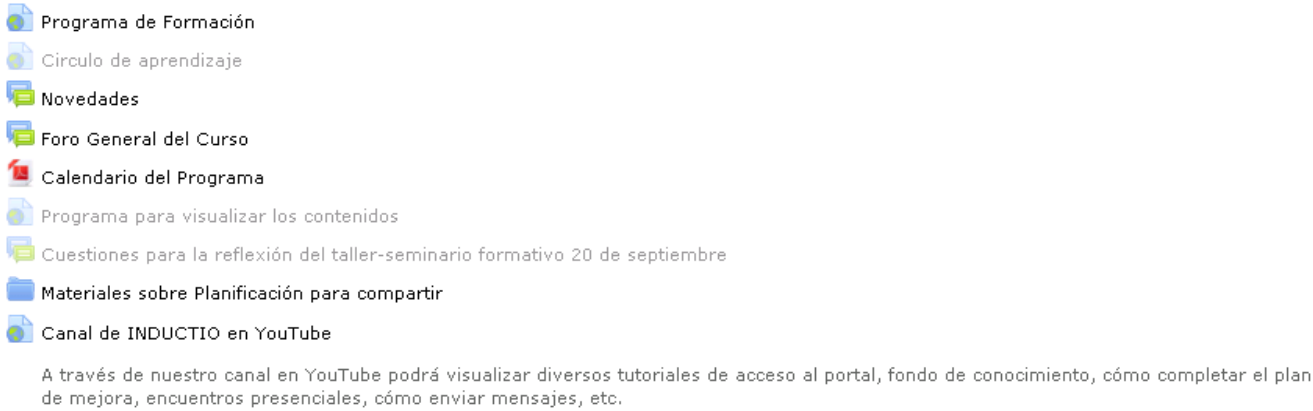

Para cada uno de los módulos de aprendizaje, de los cinco que hay en total, los mentores disponen de los siguientes apartados: contenidos, descripción de la tarea, casos prácticos, buzón para el envío de la tarea y un foro específico de este bloque o módulo temático. Los bloques o módulos de aprendizaje son los que a continuación mostramos mediante imágenes, no estando visible el quinto de ellos ya que aún no se ha llegado a éste en la formación a través de la Plataforma de aprendizaje:

Módulo 1. Estándar 1. El profesorado principiante y el aprendizaje de los estudiantes

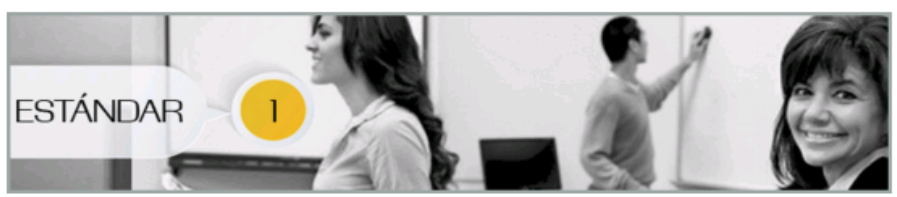

Los mentores ayudan a los docentes principiantes a establecer buenas relaciones con todos sus estudiantes, sus padres o tutores y con la comunidad a familia, pares y comunidad, promover y respetar la diversidad, crear ambientes de clases que fomenten el aprendizaje y atender a alumnado con todo tipo de necesidades de aprendizaje.

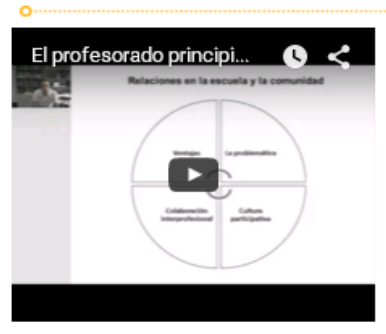

\footnotetext{
Accede a los contenidos

ill Tarea del Módulo 1

'́l Caso

Buzón de actividades 1

局 Foro del módulo 1
}

En el aula de formación para principiantes se encuentra esta visualización: 


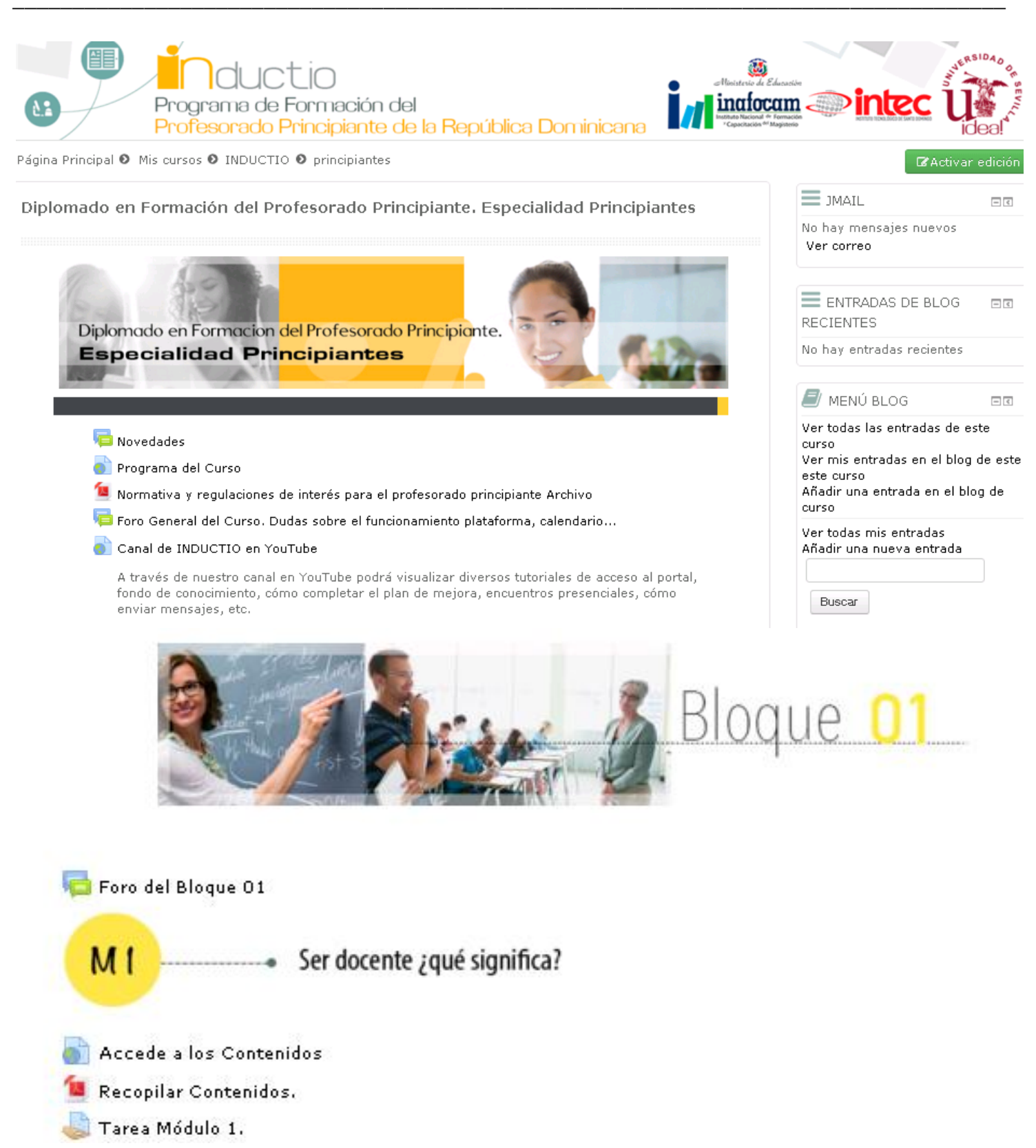

Para cada uno de los bloques, cuatro en total por el momento, ya que se van añadiendo en función de las necesidades destacadas, los docentes disponen de las siguientes herramientas de aprendizaje: contenidos, foros, tarea a realizar con plantilla para su elaboración y buzón de actividades para facilitar el envío de las mismas.

Algunas de las consultas y comentarios compartidos por mentores y principiantes giran todos en torno a la idea de localización y ubicación de archivos, recursos, carpetas, etc. Una vez transcurrió el periodo de asimilación con el uso de la plataforma las dudas son menores, llegando a ser actualmente casi inexistentes. Un ejemplo de ello son los comentarios en el inicio del curso, ahora no existen entradas en el foro al respecto.

"Necesito me expliquen cómo puedo encontrar los contenidos y tareas a realizar después de haber completado mi perfil.” (Principiante_299). 
"Debes entrar al aula de formación que está a tu izquierda en uno de los círculos y dar un click en el título del diplomado, sobre el nombre de los mentores. Ahí te aparecerán los contenidos y las tareas." (Mentor_11).

Por lo general los principiantes trabajan fácilmente con la plataforma, siendo una herramienta útil y eficaz para aprender y formarse en permanente contacto con los profesores del programa así como con sus mentores y mentoras.

"La plataforma me ayuda a ver vídeos, leer artículos, libros... desde casa o descargarlos en la computadora para poder verlos cuando no tengo internet en la escuela." (Principiante_8).

"Mi mentora me ayuda mucho con el Portal. Al principio no sabía, ahora ya manejo la plataforma sin problemas”. (Principiante_22).

Se presentan algunas evidencias fotográficas del uso y aprendizaje en el Aula virtual formativa:
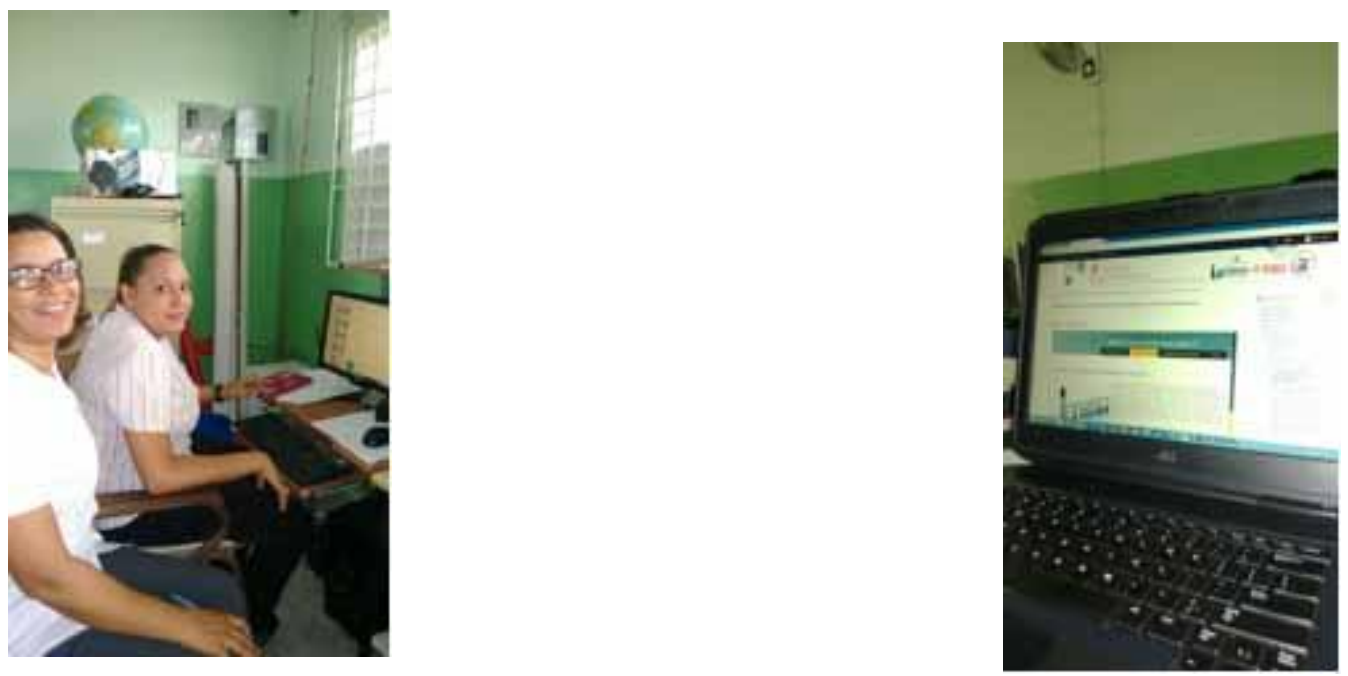

Hasta el momento, los mentores han trabajado en cuatro tareas y los principiantes en una. En la siguiente tabla mostramos los módulos en los que están estructuradas dichas tareas así como los aprendizajes y objetivos alcanzadas con ellas:

\begin{tabular}{|c|c|}
\hline Módulos de las tareas & $\begin{array}{l}\text { Aprendizajes, objetivos y efectos alcanzados tras la } \\
\text { realización de las tareas por parte de los mentores }\end{array}$ \\
\hline $\begin{array}{l}\text { Tarea } 1 . \\
\text { El }\end{array}$ & $\begin{array}{l}\text { Han sido capaces de demostrar competencia en el apoyo al } \\
\text { profesorado principiante para comprender mejor: las }\end{array}$ \\
\hline $\begin{array}{lrr}\text { principiante } & \text { y } & \text { el } \\
\text { aprendizaje } & \text { de } & \text { los } \\
\text { estudiantes } & & \end{array}$ & $\begin{array}{l}\text { relaciones con los estudiantes; las relaciones con las } \\
\text { familias; las relaciones en la escuela y comunidad; el respeto } \\
\text { a la diversidad; la creación de ambientes de aula que } \\
\text { optimizan el aprendizaje; y dar respuesta a las necesidades } \\
\text { de aprendizaje de todos los estudiantes. }\end{array}$ \\
\hline
\end{tabular}

B-learning para inducción del profesorado principiante. El caso del programa INDUCTIO en la República Dominicana. Carlos Marcelo, Carmen Gallego-Domínguez y Cristina Mayor. Página 14 de 28 


\begin{tabular}{|c|c|}
\hline $\begin{array}{l}\text { Tarea } 2 . \\
\text { Los mentores ayudan a } \\
\text { los profesores } \\
\text { principiantes a conocer } \\
\text { los contenidos que } \\
\text { enseñan }\end{array}$ & $\begin{array}{l}\text { Han demostrado competencia en el apoyo al profesorado } \\
\text { principiante para comprender mejor: los estándares } \\
\text { nacionales; el currículo y el contenido; y las áreas } \\
\text { curriculares. }\end{array}$ \\
\hline $\begin{array}{l}\text { Tarea } 3 . \\
\text { Proceso de Enseñanza- } \\
\text { Aprendizaje }\end{array}$ & $\begin{array}{l}\text { Han demostrado competencia en el apoyo al profesorado } \\
\text { principiante para comprender mejor: las buenas prácticas; el } \\
\text { desarrollo curricular; la práctica de enseñanza; y la } \\
\text { evaluación de los alumnos. }\end{array}$ \\
\hline $\begin{array}{l}\text { Tarea } 4 . \\
\text { Compromiso personal } \\
\text { y profesional }\end{array}$ & $\begin{array}{l}\text { Los mentores han utilizado habilidades de comunicación } \\
\text { eficaz para establecer relaciones profesionales y de } \\
\text { confianza con los principiantes. Los mentores han apoyado a } \\
\text { los profesores principiantes para que se desarrollen personal } \\
\text { y profesionalmente. Para ello han demostrado conocimiento } \\
\text { de las teorías de aprendizaje adulto y experiencial, han } \\
\text { promovido una práctica reflexiva y han apoyado el } \\
\text { aprendizaje autónomo de los profesores principiantes con } \\
\text { esta tarea. }\end{array}$ \\
\hline Módulos de las tareas & $\begin{array}{l}\text { Aprendizajes, objetivos y efectos alcanzados tras la } \\
\text { realización de las tareas por parte de los docentes } \\
\text { principiantes }\end{array}$ \\
\hline $\begin{array}{l}\text { Tarea 1. Ser docente, } \\
\text { ¿qué significa? }\end{array}$ & $\begin{array}{l}\text { Los docentes principiantes han alcanzado los siguientes } \\
\text { objetivos con esta primera tarea: } \\
\text {-Participar activamente en las actividades formativas con su } \\
\text { mentor o mentora. } \\
\text {-Participar en los círculos de aprendizaje. } \\
\text {-Participar activamente en el foro del Bloque } 1 \text {. } \\
\text {-Redactar al menos una entrada a la semana en su Diario } \\
\text { Reflexivo } \\
\text {-Diseñar y desarrollar su Plan de Mejora en acuerdo con su } \\
\text { mentor. } \\
\text {-Realizar la Actividad Formativa Online correspondiente al } \\
\text { Bloque 1. La actividad es la siguiente: } \\
\text { a. Leer los contenidos correspondientes a cada uno de los } \\
\text { cuatro componentes del Bloque } 1 \text {. } \\
\text { b. Seleccionar y leer al menos UN ARTíCULO online de los } \\
\text { que se ofrecen en cada uno de los componentes del Bloque. } \\
\text { c. Visionar al menos UN VÍDEOS de los que se ofrecen en } \\
\text { cada uno de los componentes del Bloque. } \\
\text { d. Redactar un texto de al menos } 3000 \text { palabras incluyendo } \\
\text { un resumen y reflexión crítica acerca de los contenidos } \\
\text { leídos y visionados. } \\
\text { e. Planificar una unidad didáctica en la que se integren los } \\
\text { componentes analizados en el Bloque I: ¿Qué significa ser } \\
\text { docente?; Gestión, motivación y disciplina en el aula; } \\
\text { Atención a la diversidad en el aula y Planificación de la } \\
\text { enseñanza. } \\
\text { El mentor o mentora hará el seguimiento de la planificación }\end{array}$ \\
\hline
\end{tabular}

B-learning para inducción del profesorado principiante. El caso del programa INDUCTIO en la República Dominicana. Carlos Marcelo, Carmen Gallego-Domínguez y Cristina Mayor. 
de la unidad didáctica Desarrollar la unidad didáctica en el aula.

f. Redactar un informe de al menos 1000 palabras que dé respuesta a las preguntas: ¿cómo se ha desarrollado? ¿cuáles fueron los aspectos positivos y mejorables? ¿cómo reaccionaron los alumnos? ¿qué propuestas de mejora se plantean?

La herramienta Plan de Mejora ayuda al profesorado principiante a establecer sus propias metas y objetivos a lo largo del primer año de enseñanza. A través de esta herramienta, el profesor principiante establece los siguientes elementos de cada Plan de Mejora: acciones a desarrollar, plazo de ejecución, apoyos y recursos necesarios, logros obtenidos, etc. El Mejora ejora es una herramienta que permite al mentor ir siguiendo los progresos de Plan de Mejora es una herramienta que per
cada uno de los profesores principiantes.

"Trabajo el plan de mejora desde mi casa en la plataforma. Mi mentora desde su casa me lo corrige y da sugerencias. Luego yo las veo en mi computadora". (Principiante_301).

"Cuando nos reunimos en los círculos de aprendizaje socializamos con el plan que he hecho y él me ayuda a cambiar los comentarios que me hace para que esté mejor de lo que lo he hecho." (Principiante_29).

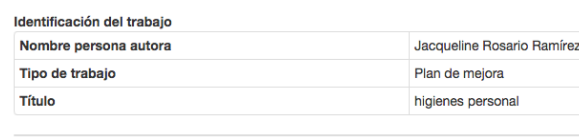

\begin{tabular}{|c|c|c|c|c|}
\hline Acciones & Plazo & Apoyos y recursos necesarios & Logros & Comentarios adicionales \\
\hline MODELAN CON MASIYA UN CEPILLO DE DIENTE & 2 SEMANAS & DE LOS PADRE & $\begin{array}{l}\text { PRACTICAN HABITOS DE HIGIENES DE MANERA } \\
\text { INDEPENDIENTE }\end{array}$ & $\begin{array}{l}\text { ELEJJ ESTE TEMA DERIVADO ALA PROBLEMATICA QUE } \\
\text { SETA PRESENTANDO EN EL AULA }\end{array}$ \\
\hline COLOREAN SAFACON & & DE LOS MAESTRO & $\begin{array}{l}\text { EXPLICAN LOS HABITOS DE HIGIENES Y CUIDADO } \\
\text { PERSONAL }\end{array}$ & \\
\hline RELLENAN CON PAPER CREPE UN INODORO & & DE LOS ORIENTADORES & & \\
\hline \multirow[t]{4}{*}{ PINTAN LOS HUTENSILO DE HIGIENES PERSONAL } & & RECURSO & & \\
\hline & & MASIYA Y TEMPERA & & \\
\hline & & PAPER CREPE Y HOJA EN BLANCO & & \\
\hline & & LAPIZ DE COLORES & & \\
\hline & & & & \\
\hline
\end{tabular}

En la siguiente tabla mostramos la estructura y los componentes de los Planes de Mejora elaborados por los docentes principiantes así como los aprendizajes obtenidos con ellos:

\begin{tabular}{|l|l|}
\hline $\begin{array}{l}\text { Estructura } \\
\text { componentes de los } \\
\text { planes de mejora }\end{array}$ & $\begin{array}{l}\text { Aprendizajes, objetivos y efectos alcanzados tras la } \\
\text { elaboración de los planes de mejora por parte de los docentes } \\
\text { principiantes }\end{array}$ \\
\hline $\begin{array}{l}\text { Nombre del autor/a y y } \\
\text { título del plan }\end{array}$ & $\begin{array}{l}\text { Permite la identificación del plan. Los principiantes ponen } \\
\text { título al plan de mejora que van a desarrollar. }\end{array}$ \\
\hline
\end{tabular}




\begin{tabular}{|c|c|}
\hline Objetivos & $\begin{array}{l}\text { Los principiantes redactan metas en forma de objetivos, es } \\
\text { decir, tras el diagnóstico de necesidades percibidas y } \\
\text { sentidas en su escuela, ellos plantean una serie de objetivos } \\
\text { para tenerlos en cuenta en su plan de mejora. }\end{array}$ \\
\hline Acciones & $\begin{array}{l}\text { Los principiantes son capaces de ejecutar el objetivo en } \\
\text { forma de acción, contemplando las posibilidades y } \\
\text { actividades necesarias para llevarlo a cabo. }\end{array}$ \\
\hline Plazo & $\begin{array}{l}\text { Marcan un plazo, un periodo de tiempo tras estudiar las } \\
\text { posibilidades de implementación y logro de dicho objetivo. }\end{array}$ \\
\hline $\begin{array}{l}\text { Apoyos y recursos } \\
\text { necesarios }\end{array}$ & $\begin{array}{l}\text { Contemplan y describen aquellos recursos -humanos, } \\
\text { materiales, espaciales, etc.- que van a necesitar para } \\
\text { implementar sus mejoras: }\end{array}$ \\
\hline Logros & $\begin{array}{l}\text { Los docentes principiantes son capaces de ir completando } \\
\text { los logros que van alcanzando a corto plazo así como de } \\
\text { describir otros a largo plazo con los que esperan cumplir el } \\
\text { objetivo en concreto sobre el que están trabajando. }\end{array}$ \\
\hline $\begin{array}{l}\text { Comentarios } \\
\text { adicionales }\end{array}$ & $\begin{array}{l}\text { Son capaces de añadir comentarios para tenerlo en cuenta a } \\
\text { la hora de implementar sus planes de mejora, por ejemplo: } \\
\text { sustituciones de docentes por bajas, excursiones, días } \\
\text { feriados, evaluaciones nacionales, etc. }\end{array}$ \\
\hline $\begin{array}{l}\text { Comentarios } \\
\text { mentor }\end{array}$ & $\begin{array}{l}\text { El mentor de cada principiante lee el plan de mejora del } \\
\text { docente, lo valora y comenta en un espacio dedicado a ello. } \\
\text { El docente lee dicho comentario y realiza los cambios y/o } \\
\text { sugerencias que su mentor le ha brindado. De esta manera } \\
\text { aprenden de manera cooperativa, colaborativa y comparten } \\
\text { experiencias, opiniones, impresiones, mejoras, etc., hasta } \\
\text { conseguir un Plan de Mejora adecuado y eficaz para su } \\
\text { realidad educativa concreta. }\end{array}$ \\
\hline
\end{tabular}

El Diario reflexivo es una herramienta que se pone a disposición del profesorado principiante para apoyar su proceso de reflexión sobre la experiencia del periodo de inducción. El diario del profesor es un recurso metodológico donde el docente realiza observaciones, entrevistas, describe lo que ocurre en clases, los materiales que utiliza, etc. Los diarios ayudan a rescatar los puntos débiles y fuertes de la práctica educativa del docente, por medio de ellos puede reflexionar sobre la práctica, ser crítico, desarrollar competencias y mejorar su práctica. Los diarios ayudan a desarrollar un pensamiento crítico y reflexivo de su práctica, y con ello pueden mejorarla.

"En el diario anoto mi preocupación de ese día. Cómo trabajo con mis estudiantes en el aula y mi mentora lo lee y me escribe o comenta o me llama y lo hablamos." (Principiante_6).

"Es una buena herramienta para escribir y guardar todo lo que me sucede en la escuela y se lo cuento luego a mi mentor o él lo lee en su plataforma compartida." (Principiante_277). 
Por Altagracia Mancebo hace 1 mes
Semana del 16-20 de noviembre Mi querida mentora: Cesalina Polanco estuvo de visita en nuestro 6 to $\mathrm{C}$. observando y brindando apoyo, con estrategias y actividades para ponerlas en practica con los estudiantes. continuamos trabajando la disciplina, asignandoles investigaciones sobre qué es y cual es la importancia de la misma, Luego, socializan en el aula. Seremos perseverantes hasta lograr un cambio totalmente positivo.

Eliminar
Por Cesalina Polanco hace 3 semanas
Altagracia ese grupo siempre deben estar trabajando porque tienen mucha energía y si los deja ociosos te hacen un caous en el aula, pero debe mantenerte cambiando las estrategias porque si mantiene las mismas siempre se desmotivan y pasa lo mismo: desorden y conflitos.

En la siguiente tabla contemplamos las temáticas que, tanto los docentes principiantes como los mentores, añaden a sus diarios reflexivos, así como el efecto en el aprendizaje y en la mejora formativa que promueve este tipo de herramientas:

\begin{tabular}{|l|l|}
\hline $\begin{array}{l}\text { Temáticas de los } \\
\text { diarios reflexivos }\end{array}$ & $\begin{array}{l}\text { Aprendizajes, objetivos y efectos alcanzados tras la } \\
\text { redacción de sus diarios reflexivos }\end{array}$ \\
\hline En el aula & $\begin{array}{l}\text { Aprenden a compartir problemáticas que les sucede en el } \\
\text { aula. También reflexionan sobre cómo mejorar su práctica } \\
\text { docente, su quehacer diario en el aula, cómo elaboran sus } \\
\text { unidades didácticas, qué ha funcionado y en qué deben } \\
\text { mejorar aún, etc. }\end{array}$ \\
\hline En la escuela & $\begin{array}{l}\text { Con respecto a la escuela, sus aprendizajes a través del } \\
\text { diario reflexivo es compartir con el resto de docentes cuáles } \\
\text { son las características de su escuela, describir el contexto y } \\
\text { las complejas situaciones contextuales en las que está } \\
\text { inmersa la escuela. Entre todos contribuyen a la mejora y al } \\
\text { entendimiento de la situación así como a la búsqueda de } \\
\text { alternativas. }\end{array}$ \\
\hline Con las familias & $\begin{array}{l}\text { Los diarios reflexivos sobre esta temática giran en torno a: } \\
\text { cómo se relacionan con las familias de sus estudiantes, cómo } \\
\text { implican a las madres en el cuidado de sus hijos en casa y } \\
\text { fuera de ella, cómo permitir su participación activa en tareas } \\
\text { de aula, cómo hacer que asistan a reuniones en el centro, etc. }\end{array}$ \\
\hline Con los estudiantes & $\begin{array}{l}\text { Los diarios reflexivos sobre esta temática giran en torno a: } \\
\text { relaciones con los alumnos, resolución de conflictos en el } \\
\text { aula, gestión del tiempo de trabajo, control de la disciplina, } \\
\text { mejoramiento de los rendimientos de los estudiantes, } \\
\text { individualización de la enseñanza, atención a la diversidad, } \\
\text { etc. }\end{array}$ \\
\hline Con el Programa & $\begin{array}{l}\text { Reflexionan y comparten temas de debates, intereses, } \\
\text { preocupaciones con las temáticas anteriores o bien con el } \\
\text { seguimiento formativo del programa, con sus aprendizajes, } \\
\text { tareas, foros, etc. }\end{array}$ \\
\hline
\end{tabular}

B-learning para inducción del profesorado principiante. El caso del programa INDUCTIO en la República Dominicana. Carlos Marcelo, Carmen Gallego-Domínguez y Cristina Mayor. Página 18 de 28 
(Q) El Fondo de conocimiento es un banco de recursos específicamente diseñado para el apoyo al profesorado principiante. Se incluyen vídeos, artículos, libros, experiencias didácticas, consejos, etc. Son por ello, útiles tanto para los docentes principiantes como para los profesores mentores.

"Es muy motivador el vernos en un vídeo con fotografias de nuestros encuentros." (Mentor_33).

"Casi todos los archivos los copio a mi computadora para enviarlas a compañeras de mi centro que no participan en el programa pero que están muy interesadas en que yo les envíe libros, artículos, vídeos de INDUCTIO”. (Principiante_99).

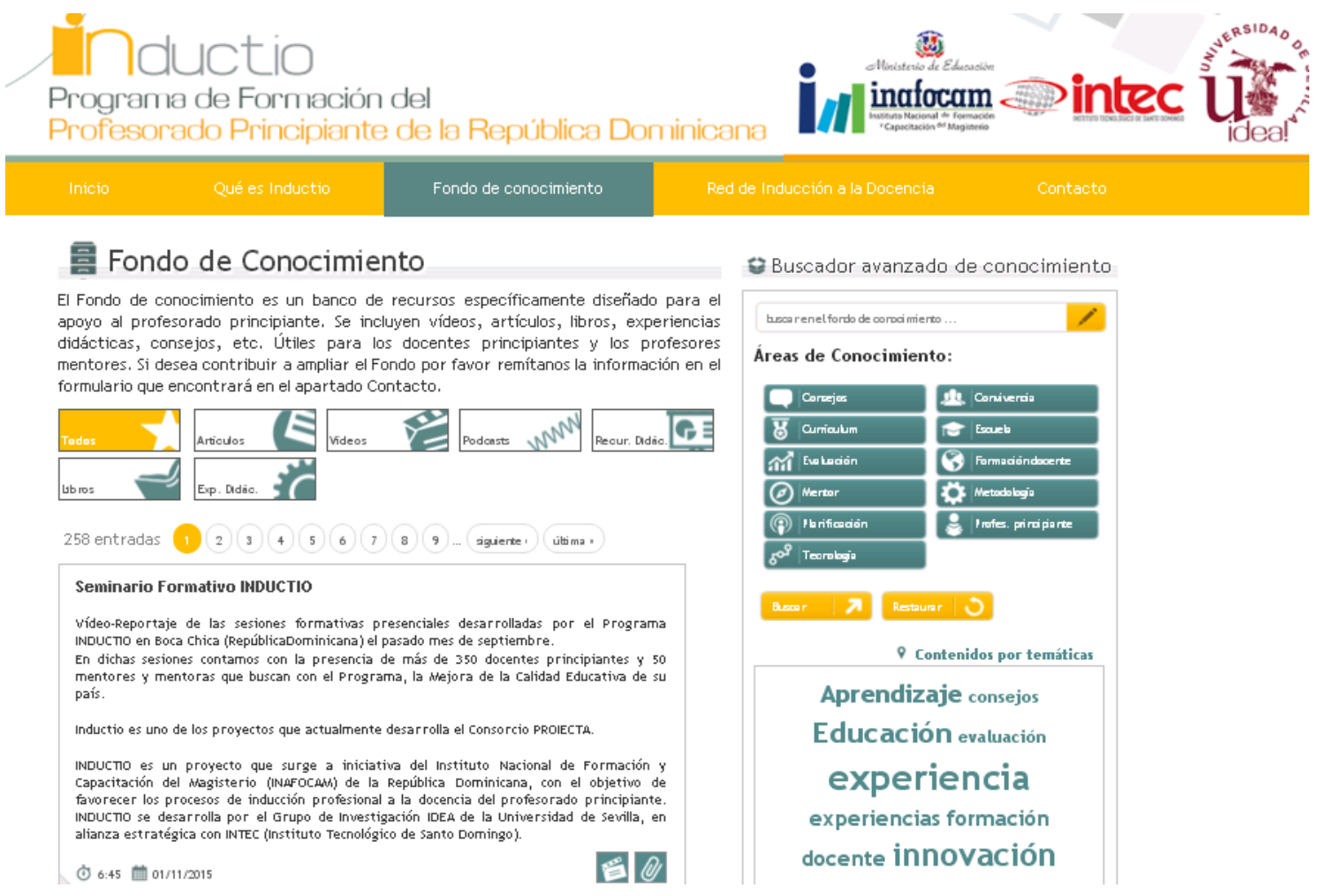

En la siguiente tabla encontramos las variables de los más de 260 recursos educativos que disponemos en el Fondo de Conocimiento de nuestro portal web: 


\begin{tabular}{|c|c|c|}
\hline $\begin{array}{l}\text { Variables } \\
\text { recursos }\end{array}$ & $\begin{array}{l}\text { Las posibilidades de } \\
\text { búsqueda: áreas } \\
\text { temáticas }\end{array}$ & $\begin{array}{l}\text { Posibilidades de aprendizaje } \\
\text { formación }\end{array}$ \\
\hline $\begin{array}{l}\text { Artículos } \\
\text { Vídeos } \\
\text { Podcasts } \\
\text { Recursos } \\
\text { didácticos } \\
\text { Libros } \\
\text { Experiencias } \\
\text { didácticas }\end{array}$ & $\begin{array}{l}\text { Consejos } \\
\text { Currículum } \\
\text { Evaluación } \\
\text { Mentor } \\
\text { Planificación } \\
\text { Tecnología } \\
\text { Convivencia } \\
\text { Escuela } \\
\text { Formación Docente } \\
\text { Metodología } \\
\text { Profesores Principiantes }\end{array}$ & $\begin{array}{l}\text { Los principiantes, mentores y cualquier } \\
\text { persona interesada en el Programa } \\
\text { Inductio pueden acceder de manera } \\
\text { libre al Fondo de conocimiento de } \\
\text { nuestro portal y encontrar más de } 260 \\
\text { recursos en diferentes formatos y } \\
\text { variables. } \\
\text { Así mismo, pueden descargarse los } \\
\text { documentos, visualizarlos en línea, } \\
\text { compartir, buscar, etc. }\end{array}$ \\
\hline
\end{tabular}

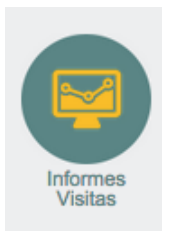

Los Informes de Visitas se realizan a lo largo del programa de inducción cuando los mentores realizan un determinado número de asistencias a las aulas de los profesores principiantes participantes en el proyecto. Cada visita debe ser planificada con antelación, estableciendo la fecha, así como el objetivo que está previsto desarrollar. Para ello es de utilidad la herramienta Plan de Mejora ya que permite realizar un seguimiento y dar sentido de continuidad a las visitas de observación que realizan los mentores. En la visita, el mentor se reúne con el profesor principiante, puede observarle mientras enseña y analizan conjuntamente la enseñanza. Al finalizar, tanto el mentor como el profesor principiante deben de redactar un INFORME DE VISITA, que da cuenta de las actividades desarrolladas.

"Yo me planifico con los principiantes y hacemos cronograma de visitas para estar al dia de todas las tareas que tenemos que hacer.” (Mentora_5).

"Mis principiantes las controlo haciendo registro de lo que hago con ellas. Anoto cuando las visito, lo que hacemos y lo que planeamos hacer en la siguiente semana o visita o reunión." (Mentor_6).

\begin{tabular}{|c|c|c|c|}
\hline \multicolumn{4}{|c|}{$\begin{array}{l}\text { CRONOGRAMA DE ACTIVIDADES } \\
\text { DEL 16 DE NOVIEMBRE AL } 20 \\
\text { REG. 10. Distrito 06. } \\
\text { Mentora: María E. Guzmán } \\
\text { Correo: mentoramaria1963@hotmail.com }\end{array}$} \\
\hline Fecha & $\begin{array}{l}\text { Nombre del } \\
\text { Maestro/a }\end{array}$ & $\begin{array}{l}\text { Actividades } \\
\text { Realizadas }\end{array}$ & Observaciones \\
\hline $16 / 11 / 2015$ & Todas de 9:00 a 12:00 & $\begin{array}{l}\text { Verificar y ayudar en la } \\
\text { plataforma }\end{array}$ & $\begin{array}{l}\text { Revisar la plataforma e ir } \\
\text { trabajando en ella en los } \\
\text { espacios libres cuando hay } \\
\text { otros maestros están sus } \\
\text { aulas. }\end{array}$ \\
\hline $17 / 11 / 2015$ & $\begin{array}{l}\text { Alba Esther Alcántara } \\
\text { Feliz }\end{array}$ & $\begin{array}{l}\text { Acompañamiento áulico y } \\
\text { ambientación }\end{array}$ & $\begin{array}{l}\text { Ha mejorado los procesos } \\
\text { de clase, su aula está } \\
\text { ambientada acorde. }\end{array}$ \\
\hline $17 / 11 / 2015$ & Aracelis Morillo Belbere & $\begin{array}{l}\text { Elaboración de carteles fijos } \\
\text { seguimiento a la labor } \\
\text { docente. }\end{array}$ & $\begin{array}{l}\text { Está realizando mejor } \\
\text { trabajo y su equipo está } \\
\text { aprendiendo. La } \\
\text { ambientación es adecuada } \\
\text { al grado. }\end{array}$ \\
\hline
\end{tabular}

B-learning para inauccion deI protesorado prıncıpıante. EI caso deI programa IINUUC I IU en Ia República Dominicana. Carlos Marcelo, Carmen Gallego-Domínguez y Cristina Mayor.

Página 20 de 28 
INFORME DE VISITA DEL 02 AL 06 DE NOVIEMBRE. DEL 2015.

\begin{tabular}{|c|c|c|c|}
\hline $\begin{array}{l}\text { Profesor } \\
\text { principiante. }\end{array}$ & Dia de la visita. & actividad & $\begin{array}{l}\text { Breve } \\
\text { comentario. }\end{array}$ \\
\hline Ines Rawlins & 03-11-2015. & $\begin{array}{l}\text { Ayudarla a } \\
\text { construir su } \\
\text { planificacion de } \\
\text { unidad didactica. }\end{array}$ & $\begin{array}{l}\text { Muestra un } \\
\text { deseo de dejarse } \\
\text { ayudar yponer en } \\
\text { pratica estos } \\
\text { conocimientos. }\end{array}$ \\
\hline $\begin{array}{l}\text { Nanci Diaz Del } \\
\text { Carmen. }\end{array}$ & 03-11-2015. & $\begin{array}{l}\text { Observacion de } \\
\text { su practica } \\
\text { pedagogica. }\end{array}$ & $\begin{array}{l}\text { Despues de } \\
\text { observar su } \\
\text { practica } \\
\text { pedagogica, } \\
\text { quedadamos en } \\
\text { acuerdos de } \\
\text { visitarla al dia } \\
\text { siguiente para } \\
\text { ayudarla a } \\
\text { construir su } \\
\text { practica } \\
\text { pedagogica. }\end{array}$ \\
\hline $\begin{array}{l}\text { Nanci Diaz Del } \\
\text { Carmen. }\end{array}$ & 005-11-2015. & $\begin{array}{l}\text { Ayudar a la } \\
\text { maestra a } \\
\text { construir su } \\
\text { planificacion de } \\
\text { unidad didactica. }\end{array}$ & \\
\hline
\end{tabular}

En la siguiente tabla mostramos la estructura de los informes de visita así como sus posibilidades de entrega y los efectos en la formación de mentores y docentes principiantes:

\begin{tabular}{|c|c|c|}
\hline $\begin{array}{l}\text { Estructura de los } \\
\text { informes de visita }\end{array}$ & $\begin{array}{l}\text { Las posibilidades } \\
\text { de entrega }\end{array}$ & Posibilidades de aprendizaje y formación \\
\hline $\begin{array}{ll}\text { - } & \text { Fecha } \\
\text { - } & \text { Nombre } \\
& \text { mentor } \\
& \text { responsable } \\
\text { - } & \text { Nombre } \\
& \text { docente } \\
\text { - } & \text { Centro } \\
& \text { educativo } \\
\text { - } & \text { Acciones } \\
\text { - } & \text { Observacio } \\
& \text { nes } \\
\text { - Otros } & \text { comentario } \\
\text { s } \\
\text { adicionales }\end{array}$ & $\begin{array}{lr}\text { Dos tipos de vías } \\
\text { de entrega de dicho } \\
\text { informe de visita: } \\
\text { por } & \text { correo } \\
\text { electrónico o } & \text { a } \\
\text { través de } & \text { la } \\
\text { plataforma } & \text { de } \\
\text { enseñanza virtual } \\
\text { (aula } & \text { de } \\
\text { formación). } & \end{array}$ & $\begin{array}{l}\text { Los mentores analizan, describen, redactan } \\
\text { y reflexionan acerca de la práctica docente } \\
\text { de cada uno de su principiantes en el lugar } \\
\text { de aula y en la escuela: cómo enseña, que } \\
\text { necesidades tiene, qué recursos necesita, } \\
\text { qué tipo de formación, cómo puede } \\
\text { ayudarlo, qué tipo de orientación necesita, } \\
\text { etc. } \\
\text { Esta herramienta ayuda a los docentes } \\
\text { principiantes a socializar con sus mentores, } \\
\text { a reflexionar sobre su práctica, a marcar } \\
\text { metas a corto plazo, a aprender de las } \\
\text { observaciones de sus mentores, etc. }\end{array}$ \\
\hline
\end{tabular}

El Foro es una herramienta que da acceso a un espacio en el que todos los profesores principiantes pueden interaccionar con su mentor y entre ellos.

En este espacio de los Foros, los mentores comparten su interés con las 
experiencias narradas por todos los principiantes, ya que éstos cuentan con un espacio de reflexión presencial para compartir preocupaciones y necesidades. Posteriormente los mentores comentan en los Foros lo que les ha aportado y enriquecido esta experiencia. También los principiantes leen estas cuestiones y responden a sus dudas, intereses, preocupaciones, etc. La finalidad de ello es que los principiantes lleven al foro sus dudas y experiencias en el aula directamente, y así los mentores pueden aconsejar, apoyar, asesorar, orientar, etc., de manera instantánea.

"Me senti orgullosa al ver a maestros principiantes narrar sus experiencias de su labor como docente, es una gran satisfacción el compartir experiencias nuevas y saber que ellos han aprendido a desenvolverse en su vida profesional.” (Mentor_41).

"El apoyo y formación institucional es fundamental, pero la actitud con el cambio que muestra el profesor novel es lo que impactará en su práctica profesional y la mejora de la calidad de la educación." (Mentor_26).

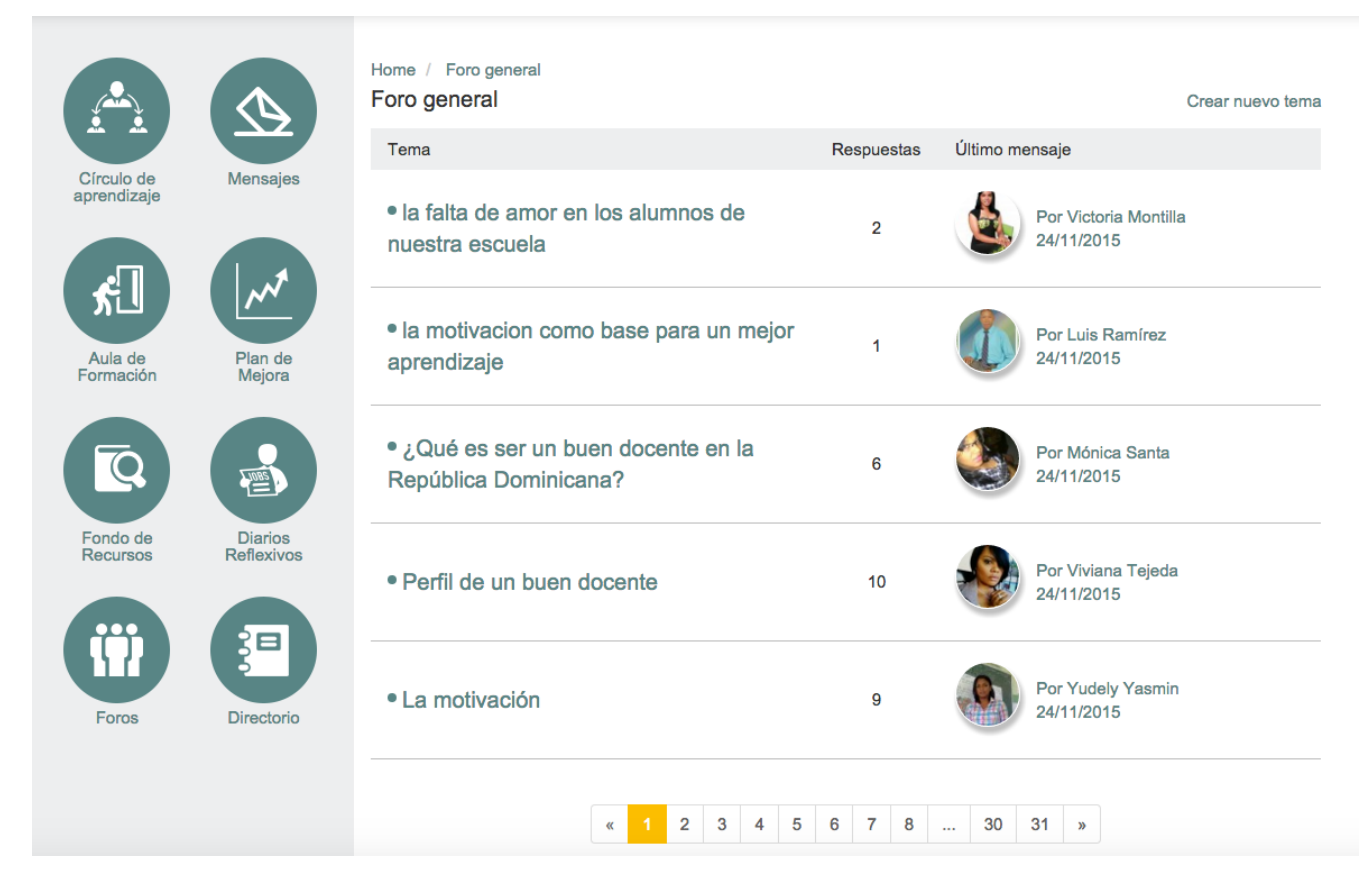

B-learning para inducción del profesorado principiante. El caso del programa INDUCTIO en la República Dominicana. Carlos Marcelo, Carmen Gallego-Domínguez y Cristina Mayor. Página 22 de 28 


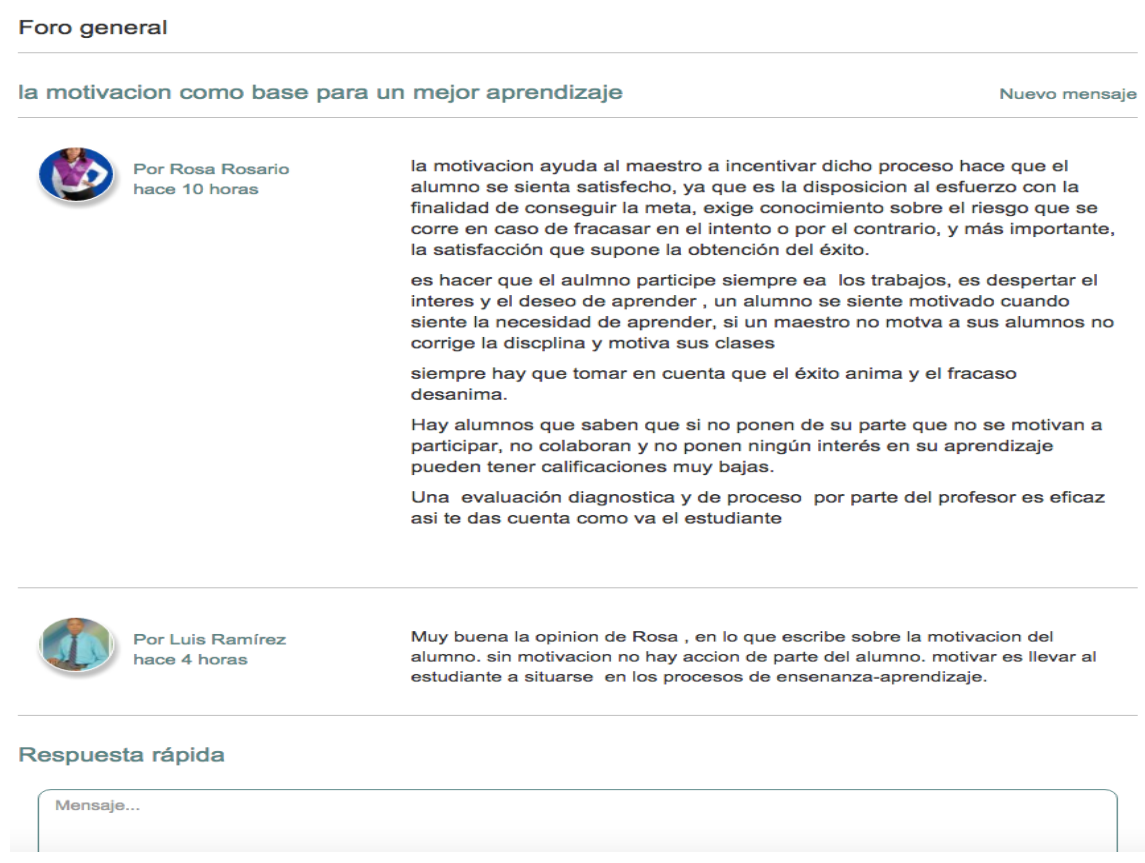

En la siguiente tabla mostramos el sistema de categoría que hemos tenido en cuenta para la descripción así como para el análisis de los mensajes en los foros, al mismo tiempo que describimos los efectos en el aprendizaje y en la formación de los docentes y mentores del Programa. Hemos tomado como referencia para la elaboración de dicho sistema las dimensiones planteadas por (Marcelo \& Perera, 2007) en su artículo sobre las interacciones didácticas en entornos de aprendizaje virtuales:

\begin{tabular}{|c|c|c|}
\hline DIMENSIONES & CATEGORÍAS & SUBCATEGORÍAS \\
\hline \multirow{3}{*}{$\begin{array}{l}\text { DIMENSIÓN } \\
\text { COGNITIVA }\end{array}$} & \multirow{2}{*}{$\begin{array}{l}\text { INICIACIÓN } \\
\text { Planteamiento inicial } \\
\text { para reconocer el } \\
\text { problema existente. }\end{array}$} & Reconocer el problema (CINIC) \\
\hline & & Sensación de confusión (preguntas) \\
\hline & \multirow{5}{*}{$\begin{array}{l}\text { EXPLORACIÓN DE } \\
\text { IDEAS } \\
\text { Búsqueda de información } \\
\text { relevante para el } \\
\text { problema. }\end{array}$} & Divergencias con el grupo (CEXPL) \\
\hline \multirow{8}{*}{$\begin{array}{l}\text { Es definida para } \\
\text { el análisis de todo } \\
\text { lo referente a la } \\
\text { teoría, a procesos } \\
\text { de interiorización } \\
\text { de contenidos y a } \\
\text { la creación de } \\
\text { conocimiento. }\end{array}$} & & $\begin{array}{lll}\begin{array}{l}\text { Divergencias } \\
\text { mensaje/participante }\end{array} & \text { con } & \text { un } \\
\end{array}$ \\
\hline & & Intercambio de información \\
\hline & & Sugerencias de reconsideración \\
\hline & & Torbellino de ideas (CINTE) \\
\hline & \multirow{4}{*}{$\begin{array}{l}\text { INTEGRACIÓN } \\
\text { CONSTRUCCIÓN } \\
\text { Concreción y acuerdo } \\
\text { con otros compañeros } \\
\text { para sintetizar y proponer } \\
\text { soluciones. }\end{array}$} & $\begin{array}{l}\text { Convergencias con otros compañeros } \\
\text { principiantes y con su respectivo } \\
\text { mentor/a }\end{array}$ \\
\hline & & $\begin{array}{l}\text { Convergencia y acuerdo con un } \\
\text { mensaje concreto }\end{array}$ \\
\hline & & Concretar ideas, sintetizar (CRES) \\
\hline & & Proponer soluciones \\
\hline
\end{tabular}

B-learning para inducción del profesorado principiante. El caso del programa INDUCTIO en la República Dominicana. Carlos Marcelo, Carmen Gallego-Domínguez y Cristina Mayor. Página 23 de 28 


\begin{tabular}{|c|c|c|}
\hline & $\begin{array}{l}\text { RESOLUCIÓN DEL } \\
\text { DILEMA/PROBLEMA. } \\
\text { Las soluciones son } \\
\text { aplicadas con coherencia } \\
\text { y viabilidad hacia el } \\
\text { cambio y la mejora. }\end{array}$ & $\begin{array}{l}\text { Aplicación de soluciones viables de } \\
\text { cambio. }\end{array}$ \\
\hline \multirow{5}{*}{$\begin{array}{l}\text { DIMENSIÓN } \\
\text { SOCIAL } \\
\text { Es aquella en la } \\
\text { que se crean } \\
\text { lazos de conexión } \\
\text { teniendo los } \\
\text { mismos intereses } \\
\text { e inquietudes de } \\
\text { aprendizaje. }\end{array}$} & \multirow{3}{*}{ AFECTIVA } & $\begin{array}{l}\text { Expresión de emociones (positivas) } \\
\text { (SAEM) }\end{array}$ \\
\hline & & $\begin{array}{l}\text { Narraciones de aspectos de la vida } \\
\text { cotidiana (Experiencias) (SANA) }\end{array}$ \\
\hline & & $\begin{array}{l}\text { Crítica, salida de tono (crítica) } \\
\text { (SACR) }\end{array}$ \\
\hline & INTERACTIVA & $\begin{array}{l}\text { Comentarios haciendo referencia a la } \\
\text { participación de otros miembros } \\
\text { (SINT) }\end{array}$ \\
\hline & COHESIÓN & $\begin{array}{l}\text { Referencias al grupo, al "nosotros" } \\
(\mathrm{SCOH})\end{array}$ \\
\hline \multirow{15}{*}{$\begin{array}{l}\text { DIMENSIÓN } \\
\text { FORMATIVA } \\
\text { Define el diseño, } \\
\text { facilitación y } \\
\text { dirección de los } \\
\text { procesos sociales } \\
\text { y cognitivos, con } \\
\text { el propósito de } \\
\text { obtener } \\
\text { resultados de } \\
\text { aprendizajes } \\
\text { significativos y } \\
\text { educativamente } \\
\text { provechosos. }\end{array}$} & \multirow{4}{*}{$\begin{array}{l}\text { DISEÑO } \\
\text { INSTRUCCIONAL Y } \\
\text { DE GESTIÓN }\end{array}$} & $\begin{array}{l}\text { Referencias al programa, currículo } \\
\text { (DGPR) }\end{array}$ \\
\hline & & Diseñar métodos (DGMT) \\
\hline & & $\begin{array}{l}\text { Utilizar medios, materiales, la } \\
\text { plataforma } \\
(\mathrm{DGME})\end{array}$ \\
\hline & & $\begin{array}{l}\text { Establecer normas } \\
\text { (DGNO) }\end{array}$ \\
\hline & \multirow{3}{*}{$\begin{array}{l}\text { FACILITAR } \\
\text { DISCURSO }\end{array}$} & $\begin{array}{lll}\text { Identificar } & \text { áreas } & \text { de } \\
\text { acuerdo/desacuerdo } & \text { (DDAD) }\end{array}$ \\
\hline & & $\begin{array}{l}\text { Promover la participación, la discusión } \\
\text { (DDPA) }\end{array}$ \\
\hline & & 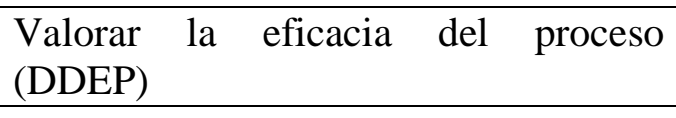 \\
\hline & \multirow{4}{*}{ TAREAS } & Cumplimiento de las tareas (DTAR) \\
\hline & & Contenido de la Tarea (DTPR) \\
\hline & & Apoyos (DTAP) \\
\hline & & Evaluación (DTEV) \\
\hline & \multirow{4}{*}{$\begin{array}{l}\text { ENSEÑANZA } \\
\text { DIRECTA }\end{array}$} & Formular preguntas (solicitud) (DIFP) \\
\hline & & $\begin{array}{l}\text { Presentar una idea nueva } \\
\text { (estructuración) } \\
\text { (DIES) }\end{array}$ \\
\hline & & $\begin{array}{l}\text { Responder preguntas explícitas } \\
\text { (DIRP) }\end{array}$ \\
\hline & & $\begin{array}{l}\text { Reaccionar (con/sin valoración) a una } \\
\text { intervención (DIRI) }\end{array}$ \\
\hline
\end{tabular}

B-learning para inducción del profesorado principiante. El caso del programa INDUCTIO en la República Dominicana. Carlos Marcelo, Carmen Gallego-Domínguez y Cristina Mayor. 


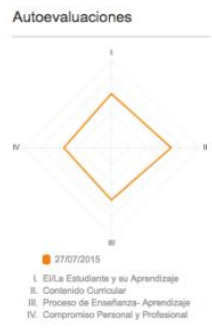

INDUCTIO proporciona al profesorado principiante la herramienta Autoevaluación, mediante la cual pueden realizar su valoración personal en relación con el nivel de logro sobre los Estándares Profesionales y del Desempeño para la Certificación y Desarrollo de la Carrera Docente correspondientes al periodo de inducción. Esta herramienta permite que los profesores principiantes se autoevalúen en varios momentos del programa.

"La autoevaluación es muy extensa pero útil para ver cómo estamos y cómo llegamos a estar.”(Principiante_222).

"Veré personalmente el progreso y cómo he terminado después de la formación " (Principiante_101).

\section{Para concluir}

Los programas de inducción para el profesorado principiante se han implantado con relativo éxito en varios países de América Latina. Argentina, Chile, Ecuador, Brasil, Colombia o Uruguay son ejemplos de países en los que sus programas de inducción tienen como objetivo fortalecer y desarrollar estrategias de acompañamiento a los que acaban de finalizar sus estudios docentes, promoviendo la capacitación continua y contribuyendo de esta manera a la mejora de la calidad de la educación (Boerr Romero, 2011a).

El programa INDUCTIO que República Dominicana ha puesto en marcha lleva funcionando tres meses. Sin embargo, a pesar del breve tiempo de existencia, los resultados positivos que se observan a través de las aportaciones en las diferentes herramientas descritas, se vislumbran tanto en lo que respecta a los aprendizajes de los principiantes como de los mentores. Tanto los mentores como los principiantes, en su totalidad, destacan la oportunidad e importancia de participar activamente en INDUCTIO por contribuir a su crecimiento, no solo profesional del campo educativo, sino personalmente. Destacan también la implicación y compromiso necesario por y para la mejora de la calidad de la educación de su país, la República Dominicana.

Las tecnologías, como hemos descrito en este artículo, están jugando un papel fundamental en el proceso de convertirse en profesor. No se trata sólo de aprender tecnologías, sino de aprender con tecnologías. En este sentido, los resultados de nuestro proyecto son coincidentes con otros estudios internacionales que han puesto de manifiesto la necesidad de apoyar el proceso de inducción con recursos asíncronos, como los foros de discusión de docentes principiantes o la creación de redes específicas para docentes principiantes, que permiten ofrecer a los docentes que se inician un plus de acompañamiento ubicuo y distribuido (Zhao et al., 2000).

Pero las tecnologías por sí solas no tendrían sentido sin las personas implicadas en el proceso de inducción. Los mentores son los protagonistas de este programa, quienes como comentaban Orland-Barak y Yinon (2005), a veces son expertos y a veces principiantes. Para estos profesionales, las tecnologías están jugando también un papel de apoyo social, formativo y cognitivo. Estos aspectos emocionales, afectivos y sociales

B-learning para inducción del profesorado principiante. El caso del programa INDUCTIO en la República Dominicana. Carlos Marcelo, Carmen Gallego-Domínguez y Cristina Mayor. 
están continuamente presentes en sus conversaciones. Pero las tecnologías les comprometen a redactar sus pensamientos e ideas para poder compartirlas. Y aquí se está generando un proceso de maduración cognitiva que lo está facilitando el programa.

El programa INDUCTIO está permitiendo que profesores y mentores den un salto cualitativo en la incorporación de las tecnologías digitales en sus procesos de aprendizaje y desarrollo profesional. Hay que tomar en consideración las dificultades de un país como República Dominicana que, pese al esfuerzo que viene realizando en los últimos años de dedicar un 4\% del PIB a educación, se encuentra con graves problemas de conectividad. Y pese a estos inconvenientes, mentores y principiantes están haciendo un uso formativo de las tecnologías digitales, están mejorando sus competencias digitales y como consecuencia sus oportunidades de aprendizaje.

Presentación del artículo: 26 de noviembre de 2015

Fecha de aprobación: 10 de enero de 2016

Fecha de publicación: 30 de enero de 2016

Marcelo, C., Gallego-Domínguez, C., \& Mayor, C. (2016). B-learning para inducción del profesorado principiante. El caso del programa INDUCTIO en la República Dominicana. RED. Revista de Educación a Distancia. 48(4). Consultado el (dd/mm/aaaa) en http://www.um.es/ead/red/48/marcelo.pdf

\section{Bibliografía}

Bang, E. (2013). Hybrid-Mentoring Programs for Beginning Elementary Science Teachers. International Journal of Education in Mathematics, Science and Technology, 1(1), 1-15.

Barrera, A., Braley, R. T., \& Slate, J. R. (2010). Beginning teacher success: an investigation into the feedback from mentors of formal mentoring programs. Mentoring \& Tutoring: Partnership in Learning, 18(1), 61-74. Recuperado de http://doi.org/10.1080/13611260903448383

Bickmore, D. L., \& Bickmore, S. T. (2010). A multifaceted approach to teacher induction. Teaching and Teacher Education, 26(4), 1006-1014. Recuperado de http://doi.org/10.1016/j.tate.2009.10.043

Boerr Romero, I. (2011a). Acompañar los primeros pasos de los docentes. La construcción de una política de inserción al ejercicio profesional. Santiago de Chile: Santillana.

Boerr Romero, I. (2011b). Mentores y Noveles: Historias del Trayecto. Santiago de Chile: Santillana.

Bransford, J., Derry, S., Berliner, D., \& Hammersness, K. (2005). Theories of learning and their roles in teaching. En L. Darling-Hammond \& J. Bransford (Eds.), Preparing teachers for a changing world (pp. 40-87). San Francisco: Jossey Bass.

B-learning para inducción del profesorado principiante. El caso del programa INDUCTIO en la República Dominicana. Carlos Marcelo, Carmen Gallego-Domínguez y Cristina Mayor. 
Cox, C., Beca, C. E., \& Cerri, M. (2014). Docentes para una educación de calidad en América Latina: problemas y orientaciones políticas. En J. Díaz de la Torre (Ed.), Realidades y Prospectiva Educativa (pp. 41-92). México: SNTE.

Fetherston, T., \& Lummis, G. (2012). Why Western Australian Secondary Teachers Resign. Australian Journal of Teacher Education, 37(4), 1-20.

Jensen, B., Sandoval-Hernández, A., Knoll, S., \& González, E. J. (2012). The Experience of New Teachers: Results from TALIS 2008. Organisation for Economic, Co-operation and Development (OECD). Recuperado de http://dx.doi.org/10.1787/9789264120952-en

Kelly, N., Reushle, S., Chakrabarty, S., \& Kinnane, A. (2014). Beginning teacher support in Australia: Towards an online community to augment current support. Australian Journal of Teacher Education, 39(4), 68-82. Recuperado de http://doi.org/10.14221/ajte.2014v39n4.6

Marcelo, C., \& Perera, V. H. (2007). Comunicación y aprendizaje electrónico: la interacción didáctica en los nuevos espacios virtuales de aprendizaje. Revista de Educación, No 343, pp. 381-429.

Marcelo, C. (Coord.) (2008): Profesorado Principiante. Inserción Profesional. Barcelona. Octaedro.

Marcelo, C., \& Vaillant, D. (2009). Desarrollo profesional docente. Madrid, Narcea.

Orland-Barak, L., \& Yinon, H. (2005). Sometimes a novice and sometimes an expert: mentors' expertise as revealed through their stories of critical incidents. Oxford Review of Education, 31(4), 557-579.

Robles Vásquez, H. V., Mendieta Melgar, G., Zendejas Frutos, L., Medrano Camacho, V., Errandonea, G., Luaces, M., \& Peré, N. (2013). La formación en el desempeño de la docencia. En Organización de Estados Iberoamericanos para la Educación, la Ciencia y la cultura (OEI) (Ed.), Miradas sobre la Educación en Iberoamérica. Desarrollo profesional docente y mejora de la educación. Metas Educativas 2021 (pp.155-224). Madrid. Recuperado de http://www.oei.es/publicaciones/InformeMiradas2013.pdf

Romano, M. E. (2008). Online discussion as a potential professional development tool for first-year teachers. Technology Pedagogy and Education, 17(1), 53-65. http://doi.org/10.1080/14759390701847591

White, S. (2011). Preparing teachers for rural and regional settings the RRRTEC project. Curriculum \& Leadership Journal, 9(20). Recuperado de http://www.curriculum.edu.au/leader/the_rrrtec_project,33881.html?issueID=12471

Vaillant, D., \& Marcelo, C. (2015). El A, B, C y D de la formación docente. Madrid, Narcea.

B-learning para inducción del profesorado principiante. El caso del programa INDUCTIO en la República Dominicana. Carlos Marcelo, Carmen Gallego-Domínguez y Cristina Mayor. 
Zhao, Y., Englert, C. S., Chen, J., Jones, S. C., \& Ferdig, R. E. (2000). The Development of a Web-based Literacy Learning Environment: A Dialogue Between Innovation and Established Practices. Journal of Research on Computing in Education, 32(4), 435-454.

\section{Agradecimientos}

Los autores desean mostrar su agradecimiento al Instituto Nacional de Formación y Capacitación del Magisterio (INAFOCAM) de la República Dominicana y a la Universidad INTEC por su apoyo para el desarrollo de este proyecto. Igualmente desean agradecer el esfuerzo y dedicación de todos y cada unos de los mentores y mentoras así como del profesorado principiante participante en el programa. 